REVISTA DE DERECHO UNED, núm. 6, 2010

\title{
HACIA UN TRATADO DE DERECHO ADMINISTRATIVO ROMANO
}

\author{
ANTONIO FERNÁNDEZ DE BuJÁN \\ Catedrático de Derecho Romano de la Universidad \\ Autónoma de Madrid
}

Resumen: Hay que reconstruir los conceptos y dogmas propios de la Administración Pública Romana, a fin de colmar la laguna que se produce en este sector del Ordenamiento Jurídico, dada la inexistencia, en la literatura romanística, de una obra de esta naturaleza y en atención a lo que ello supone de conexión entre la investigación histórica y la dogmática moderna, tan necesaria para el progreso de la Ciencia del Derecho.

Palabras clave: Administración Pública Romana. Instituciones. Hechos y Actividad de orden administrativo. Experiencia administrativa romana.

Abstract: It is necessary to rebuild the concepts and dogmas particular to the Roman Public Administration in order to replete the void that this area of the legal system suffers due to the non-existence of a work of this nature in romanistic literature, and having in mind what it would mean as a connection, very desirable for the progress of the Science of Law, between historical investigation and modern dogmatic.

Key words: Roman Public Administration, Institutions, administrative Facts and Activity, Roman administrative experience.

Sumario: A) Premisas programáticas.-B) La necesaria reconstrucción de los conceptos y dogmas propios de la Administración Pública Romana.-C) Ámbito de la experiencia administrativa romana: Colonias. Municipios. Provincias. Competencias atribuidas a la Administración Pública. Concesiones administrativas. Gestión de servicios 
públicos. Tutela de la salud pública. Política fiscal. Policía y Orden público. Aguas, minas y vías públicas. Empleados públicos. Jurisdicción administrativa. El interdicto como providencia administrativa urgente. Eficacia y validez de los actos administrativos. Dominio Público. Utilitas publica. Expropiación forzosa.

\section{A) PREMISAS PROGRAMÁTICAS}

El título que sirve de rúbrica al presente trabajo responde al propio tiempo, a un proyecto compartido con colaboradores en varios Proyectos de Investigación ejecutados sobre esta temática, y autores de aportaciones específicas en el ámbito de la experiencia administrativa y fiscal romana ${ }^{1}$, y a una idea conductora que pone el acento en la necesaria reconstrucción del derecho administrativo romano, con lo que ello comporta, por otra parte, de conexión entre la investigación histórica y la dogmática moderna, tan conveniente para el progreso de la Ciencia del Derecho. La rúbrica del estudio obedece asimismo a un pretendido carácter programático al incidir en la ne-

1 En los últimos años, se han leído, bajo mi dirección, diez Tesis Doctorales, en temática de Derecho Administrativo y Fiscal Romano, así como se han publicado, diversos estudios específicos sobre esta materia, que se han materializado en una Colección de Monografías que, bajo ese mismo título, han ido viendo la luz en la Editorial Dykinson, y cuyo objetivo último va dirigido a colmar, en un futuro próximo, la laguna - denunciada ya en siglos pasados por Ihering y Schulz, entre otros relevantes romanistas-, y el reto científico, que supone la inexistencia de un Tratado de Derecho Administrativo y Fiscal Romano. Al respecto cabe señalar: CASTÁN PÉREZ, Régimen jurídico de las concesiones administrativas en Derecho Romano. Prólogo. A. Fernández de Buján. (1996); ALBURQUERQUE, La protección o defensa del uso colectivo de las cosas de dominio público .Prólogo A. Fernández de Buján (2002); PENDÓN MELÉNDEZ, Régimen jurídico de la prestación de servicios públicos en derecho romano. Prólogo A. Fernández de Buján (2002); GIMÉNEZ BARRIOCANAL, La actividad económica en Derecho Romano. Análisis contable. Prólogo A. Fernández de Buján (2004); RODRIGUEZ ENNES, Gallaecia: romanización y ordenación del territorio. Prólogo A. Fernández de Buján (2004); PONTE ARREBOLA, Régimen jurídico de las vías públicas en Derecho Romano Prólogo A. Fernández de Buján (2007); VARELA GIL, El estatuto jurídico del empleado público en Derecho Romano. Prólogo A. Fernández de Buján (2007); AGUDO RUIZ, El advocatus fisci en Derecho Romano. Prólogo A. Fernández de Buján (2007); MALAVÉ OSUNA, Régimen jurídico financiero de las obras públicas en Derecho Romano: los modelos privado y público de financiación. Prólogo A. Fernández de Buján (2007); LÓPEZ HUGUET, Régimen jurídico del domicilio en Derecho Romano. Prólogo A. Fernández de Buján (2008); GERÉZ KRAEMER, El derecho de aguas en Roma. Prólogo A. Fernández de Buján (2008); BRAVO BOSCH, El largo camino de los hispani hacia la ciudadanía. Prólogo A. Fernández de Buján (2009); ZAMORA MANZANO, Algunos aspectos sobre el régimen fiscal aduanero en el Derecho Romano: Reglamentación jurídica del portorium, control de mercancías y comiso por fraude fiscal (2009). 
cesidad y en el reto científico que supone colmar la laguna que se produce en este sector de la ciencia del derecho, dada la inexistencia, en la literatura romanística, de una obra de esta naturaleza, lo que resulta, por otra parte, en verdad sorprendente, a la altura de los tiempos en que nos encontramos, si nos atenemos:

a) Al principio de la unidad de la ciencia jurídica, en relación con la que cabría remontarse a la cita clásica del texto de Ulpiano, D.1.1.1.2, acerca de las dos posiciones para el estudio del derecho: "Huius studi duae sunt positiones, publicum et privatum. Publicum ius est, quod ad statum rei Romanae spectat, privatum, quod ad singulorum utilitatem; sunt enim quaedam publice utilia, quaedam privatim», en atención a la utilidad pública o privada de los intereses en juego, y

b) A la propia unidad del Derecho Romano como Ordenamiento jurídico global de toda la experiencia jurídica del pueblo y del territorio romano, lo que ha hecho a escribir a Schulz, en sus Principios, que no resulta justificada la separación rigurosa de las normas pertenecientes al ius publicum y al ius privatum, que se encuentran estrechamente relacionadas, entre sí, en la práctica, lo que supuso graves perjuicios, entre los que se cuenta la falta de una mayor atención por la jurisprudencia romana a las cuestiones de Derecho público, y ello con independencia de que el planteamiento teórico, la aplicación práctica y la elaboración científica de la parte más valiosa y perenne del pensamiento jurídico romano sea la correspondiente al derecho de juristas clásico, y que éste se desarrolle de manera prevalente en el ámbito del Derecho privado.

En los días en que se redactaban estas páginas, de finales del año 2009, formé parte, como Vocal, del Tribunal que juzgaba una Cátedra de Derecho Administrativo de la Universidad Autónoma de Madrid, para la que se propuso por unanimidad al Prof. Jimenez de Cisneros. En el acto de constitución, comenté con mis colegas, catedráticos de Derecho Administrativo de distintas universidades españolas, la celebración, a la sazón, de unas Jornadas de Derecho Administrativo, Fiscal y Medioambiental en la Universidad San Pablo Ceu de Madrid, al tiempo que les mostraba el díptico de la Editorial Dykinson, en el que figura la Colección de Derecho Administrativo Romano, integrada por un total de 24 monografías, 14 de las cuales están ya publicadas y 13 se encuentran en preparación o en prensa. A la vista del elenco de títulos, uno de los miembros del Tribunal comentó, con el asentimiento de los presentes, que la temática de estos estudios mo- 
nográficos, se correspondía, en síntesis, con el programa de Derecho Administrativo que se imparte en las universidades españolas. Creo que, aunque haya sido realizado en el marco de una sesión de oposiciones a cátedra, se trata de un reconocimiento significativo por parte de un prestigioso colega de Derecho Administrativo vigente.

\section{B) LA NECESARIA RECONSTRUCCIÓN DE LOS CONCEPTOS Y DOGMAS PROPIOS DE LA ADMINISTRACIÓN PÚBLICA}

Si bien es evidente la influencia que la Revolución Francesa tuvo en los sistemas jurídicos y políticos de cultura occidental, lo que en el caso del Derecho administrativo se manifestó en la teorización que originó la ciencia del Derecho administrativo y en la elaboración de Códigos unitarios y autónomos de Derecho administrativo, no parece acertada, sin embargo, la opinión de que el Derecho administrativo moderno surge en el siglo XIX ${ }^{2}$. Tal afirmación se debe, en parte, a la ausencia de una reconstrucción dogmática del Derecho administrativo romano. La problemática correspondiente a la administración ciudadana romana espera todavía ser estudiada en profundidad, y no sólo por un mero interés histórico, sino para conocer mejor el ordenamiento jurídico contemporáneo, que en buena medida es tributario de instituciones, hechos y actividad de orden administrativo que fueron conocidos y regulados en el ámbito estatal, provincial y municipal de la comunidad política romana. Y si bien en el campo del derecho no existen reglas, instituciones ni dogmas inmutables, sino sólo productos históricos y contingentes, sí existe, también en el ámbito del Derecho administrativo, como intentaremos poner de relieve, continuidad histórica e interdependencia.

Cuando estudiosos actuales de otras disciplinas de Derecho público deciden estudiar las aportaciones puntuales de la investigación histórica correspondientes a la experiencia administrativa romana, y esforzarse en entender el lenguaje de los romanistas, en ocasiones hermético y no fácilmente comprensible para los no especialistas, o bien acuden directamente a las fuentes romanas, suelen constatar la

\footnotetext{
${ }^{2}$ El Derecho Administrativo francés, escribe P. LAROQUE, RHDFE, 1974, pp. 764 y ss., es también un producto de la historia. La filosofía política de la Revolución implica que el Estado está sometido al Derecho, por lo que debe someterse a las normas jurídicas que se impone a sí mismo. La justificación de la existencia del Derecho Administrativo radica en que el interés general debe estar por encima de los intereses particulares. Derecho Administrativo e historia han estado en el pasado y están en el presente estrechamente ligados.
} 
existencia de una compleja problemática administrativa en el seno de una sociedad, como la romana, en constante expansión y desarrollo, en la que se encuentran planteadas y satisfactoriamente resueltas las grandes cuestiones teóricas y prácticas del Derecho administrativo actual, como ha sido subrayado por IMPALLOMENI: «Para tener una idea de los problemas baste pensar en una ciudad moderna y en sus órganos, teniendo presente que las líneas esenciales han permanecido sustancialmente idénticas ${ }^{3} »$.

Pues bien, cabría remontarnos a Ihering quien, ya en 1854, en su Espíritu del Derecho Romano, señala la oportunidad de la reconstrucción del Derecho público y administrativo romano ${ }^{4}$. En 1862 Serrigny, profesor de Derecho Administrativo de Dijon, publica un Derecho Público y Administrativo Romano en el que afirma que «el origen principal de todas nuestras instituciones sobre el Derecho público, administrativo, económico y social es el Derecho Romano, tal y como se contiene en los Códigos Teodosiano y Justinianeo» ${ }^{5}$. En 1881 Marquard rubrica el primeros de los tomos, en los que procede al análisis de la administración de los territorios conquistados por Roma, con el expresivo título de «Sistema administrativo del Estado Romano ${ }^{6}$. Casi cien años después de la obra de Ihering, en 1939, Schulz en sus Principios de Derecho Romano vuelve a reiterar que la inexistencia de un Tratado de Derecho administrativo romano constituye una laguna de nuestra ciencia ${ }^{7}$. Dicha idea es subrayada de nuevo por Koschaker, en su Europa y el Derecho Romano, en 1947: «Falta por construir una historia de los conceptos y de los dogmas de Derecho público romano, realizada dogmáticamente y con un método histórico, es decir, con las modernas técnicas de la ciencia del derecho ${ }^{8}$, por Riccobono en 1964, en su conocido estudio sobre la necesidad de reconstruir la estructura administrativa romana, Il problema della ricostruzione delle structture amministrative roma-

\footnotetext{
3 IMPALLOMENI, L'inquadramento giuridico delle colonie e dei municipi (Julia Concordia e Opitergium) nell'ambito del impero romano. Veneto orientale 1, Portogruaro 1983, pp. 32 y ss. Vid. asimismo en FERNÁNDEZ DE BUJÁN, A., Perspectivas de estudio en temática de Derecho Administrativo romano surgidas a tenor del pensamiento y de la obra de Giambattista Impallomeni, en Index 26, 1998, pp. 463-487.

${ }^{4}$ IHERING, Geist des römischen Rechts I-III ${ }^{6}$, Leipzig, 1906-1923.

5 Serrigny, Droit public et administratif romain. Institutions politiques, administratives, économiques et sociales de l'Empire romain du IVe au VIe siècle. París,

6 Marquart, Römische Staatsverwaltung. Leipzig, 1881-1885.

7 SCHULZ, Principios de Derecho Romano, trad. de M. ABELLAN VELASCO, Civitas, 1990.

${ }^{8}$ KOSCHAKER, Europa y el Derecho Romano, tr. De Santa Cruz, Madrid, 1955.
} 1862. 
ne$^{9}$, por Impallomeni, en 1983, al afirmar que el sistema de administración ciudadana y el sistema municipal del Imperio esperan todavía por ser estudiados, y más que por un mero interés histórico, para entender mejor los ordenamientos jurídicos contemporáneos ${ }^{10}$, y por Nocera en $1987^{11}$. Y ya finalmente, por hacer alguna referencia a las dos últimas décadas, cabría mencionar el Congreso Internacional sobre el tema «I rapporti contrattuali con la pubblica amministrazione nell'esperienza storico-giuridica», celebrado en Torino en 1994, y el novísimo estudio de Crifó, Il compito del romanista, publicado en la Revista Internacional de Derecho Romano en octubre del 2008, en el que el autor dedica la mitad de su aportación a glosar lo que denomina «excelentes perspectivas de investigación en materia de D. Advo. Romano» ${ }^{12}$.

Y no se trata, a mi juicio, de pretender reconstruir el Derecho administrativo romano como un apriorismo científico por su interés histórico, es que la conexión entre el Derecho administrativo romano y el vigente existe, aunque no haya sido estudiada debidamente y así en los temas señalados por IMPALLOMENI, y en otros conexos con los mismos, como responsabilidad administrativa, saneamiento financiero, organización de la burocracia estatal, privilegios de la administración o garantías de los ciudadanos, se produce una continuidad histórica en el planteamiento de las cuestiones, cuya resolución se aborda en Derecho romano mediante soluciones de sorprendente modernidad ${ }^{13}$. Digámoslo ahora con palabras de KOSCHAKER

9 RICCOBONO, Il problema della ricostruzione delle structture amministrative romane, in Synteleia V. Arangio-Ruiz, 1964, pp. 663 y ss.

10 IMPALLOMENI, L'inquadramento giuridico delle colonie e dei municipi, cit., p. 38 .

11 NOCERA, Il centralismo administrativo del Tardo-Impero, Atti dell'Accademia romanistica constantiniana. VIII Congresso Internazionale degli studi di Perugia, pp. 599 y ss. Se pronuncia NOCERA sobre cuestiones como la existencia o no de un Derecho Administrativo Romano, la posibilidad de hablar de ciencia del Derecho Administrativo y el papel de la jurisprudencia y de la legislación en materia de Derecho Administrativo.

12 Crifó, Il compito del romanista, la Revista Internacional de Derecho Romano, octubre del 2008.

13 En España, entre los autores que han destacado la importancia o resaltado la carencia de estudio del Derecho romano, cabe mencionar a: MURGA, Conceptos romanos básicos para el moderno Derecho Administrativo, in Romanitas, Río de Janeiro, 1970; Id., La popularidad de las acciones en las leyes municipales de la Betica, en RIDA, 1991, 225, en donde se afirma que todo el ordenamiento jurídico nace del mismo magma original: el ius civile y el edicto de los pretores; las normas jurisprudenciales, así como los plebiscitos y las leges datae que constituyen el moderno ius publicum romano, normatividad al principio incipiente y luego extensa, inabarcable y tan vigorosa que los particulares no podrán nunca cambiarla con sus pactos y condi- 
escritas en su Europa y el Derecho Romano, en 1947: «Falta por construir una historia de los conceptos y de los dogmas de Derecho público romano, realizada dogmáticamente y con un método histórico, es decir, con las modernas técnicas de la ciencia del derecho» ${ }^{14}$, y agreguemos la precisión de BISCARDI realizada en 1989 en el discurso pronunciado con ocasión de su Doctorado Honoris Causa por la Universidad Complutense, titulado «El Derecho y la Ciencia del Derecho en los umbrales del año 2000»: Frente a una moderna corriente de opinión que tiende a colocar el arte en la dogmática y la ciencia en la Historia del Derecho, argumentando que la dogmática es una doctrina puramente instrumental, técnica de la interpretación y de la aplicación de las normas de un sistema impuesto ex auctoritate, por lo que la verdadera ciencia no puede ser más que la historia, puesto que ésta no tiene un fin práctico, sino sólo el de la búsqueda de la verdad, no seré yo ciertamente, quien niegue — continúa BISCARDI— la importancia fundamental de la historia en el conocimiento del derecho, que es esencialmente un fenómeno histórico, pero lo que en modo alguno me persuade es que se pueda negar a la dogmática el carácter de ciencia, en el sentido moderno de la palabra, objetando que la dogmática no tendría la función de buscar la verdad, sino tan sólo la función de ordenar y comprender, en todo caso, que el análisis de los principios e instituciones es una actividad científica ${ }^{15}$.

Asimismo, cabe señalar que destacados administrativistas actuales, entre los que cabe citar en la doctrina española a GARCÍA DE ENTERRÍA, VILLAR PALASÍ, GALLEGO ANABITARTE, PARADA VÁZQUEZ, PAREJO ALFONSO, etc., han destacado y valorado en instituciones concretas la influencia del Derecho romano, que había sido asimismo subrayada en el siglo XIX por DOU y BASSOLS y por COLMEIRO, entre otros autores. Sin embargo, a mi juicio, es superior la influencia ejercida por el Derecho Romano en el desarrollo y en la evolución del Derecho administrativo moderno, y en el Dere-

ciones...; TORRENT, A propósito de la Legislazione regionale di Giustiniano, Labeo 29, 1983, pp. 177 y ss., escribe «El Derecho administrativo es uno de los sectores peor estudiados de toda la amplia experiencia jurídica romana... y sin embargo los problemas administrativos son muy interesantes y en gran parte están aún por aclarar...», CAMIÑAS, en un artículo titulado Hacia donde camina el estudio del Derecho Romano, en el Boletín del Colegio de Abogados de Lugo 6, 1996, 5, afirma, por su parte, que Roma conoció el Derecho administrativo territorial y contó con una ciencia del derecho administrativo desde la segunda mitad del siglo II, cuya creación y elaboración es una de las principales obras del Principado...

${ }^{14}$ KOSCHAKER, Europa y el Derecho Romano, tr. De Santa Cruz, Madrid, 1955.

15 BISCARDI, El Derecho y la Ciencia del Derecho en los umbrales del año 2000, Madrid, 1989, p. 21. 
cho público en general, que la que ha sido reconocida por la actual doctrina administrativa ${ }^{16}$.

Hoy nadie niega que haya existido en Roma, organización administrativa, estructura administrativa y Administración Pública. Como ha sido puesto de relieve, es la administrativa la primera función histórica de cualquier comunidad política, antes incluso que la legislativa o la jurisdiccional, por lo que es la propia historia, en expresión de García de Enterría, no sólo la prueba de la existencia permanente de un Derecho Administrativo, sino también de la continuidad de buena parte de sus técnicas ${ }^{17}$.

El estudio de los principios, de las normas y de las instituciones propias de la Administración Pública romana, deberá hacerse, a mi juicio, desde una previa depuración filológica de los textos, conforme a los postulados del método histórico-crítico, cuando ello resulte necesario y, en todo caso, de acuerdo con los criterios la lógica y la interpretación inherentes al método dogmático, desde el convencimiento de que tan científico es el método dogmático como lo es el método histórico. No se trataría ,sin embargo, de plantearse necesariamente en cada estudio que se realice, el problema de la continuidad o discontinuidad histórica entre la solución romana y la solución actual, en el campo de la experiencia administrativa, ni de encasillar los resultados del estudio sobre la administración pública romana en el marco del actual derecho administrativo, ni mucho menos de actualizar la normativa administrativa romana en clave de un redivivo neopandectismo, sino de reconstruir las instituciones administrativas, en el marco de una metodología histórico-dogmática, de estudiar, en definitiva, el derecho como producto histórico, que vaya más allá de una mera perspectiva historicista o economicista, sin renunciar, cuando fuere necesario, y con la adecuada advertencia, a la utiliza-

16 GARCÍA DE ENTERRÍA, dos Estudios sobre la usucapión en Derecho Administrativo, Madrid, 1974; VILLAR PALASÍ, s.v. «Concesiones Administrativas», en Nueva Enciclopedia Jurídica IV, Barcelona, 1952; GALLEGO ANABITARTE, MENÉNDEZ REXACH, DÍAZ LEMA, El Derecho de aguas en España, Madrid, 1986; PARADA VAZQUEZ, Derecho Administrativo, Bienes públicos y urbanismo III'2, Madrid, 1989; PAREJO ALFONSO, Dominio Público: un ensayo de reconstrucción de su teoría general, RAP, 3, 1983, pp. 100 y ss.; MORILLO VELARDE, Dominio Público, Madrid, 1992.

17 En este sentido se pronuncia el administrativista español E. GARCÍA DE ENTERRÍA, Dos estudios sobre la usucapión en Derecho Administrtivo ${ }^{2}$, Tecnos, 1974, pp. 19 y ss., cuando afirma: «...bastaría observar que es la administrativa la primera función histórica de cualquier Estado o forma política, de modo que precede a todas las demás (legislativa, jurisdiccional)...La Historia prueba no sólo la existencia permanente de un Derecho Administrativo, sino también la continuidad de buena parte de sus técnicas». 
ción de términos y expresiones propias del derecho actual, para designar ideas y realidades acaecidas en la experiencia romana.

Planteadas así las cuestiones de la historicidad del Derecho, de la unidad de la ciencia jurídica y del carácter científico de la dogmática, podríamos volvamos a la primera premisa de la cuestión, que podría ser ésta: ¿existió en Roma un Derecho administrativo?

Constituye una afirmación común de la moderna publicística del Derecho administrativo, la de que no se puede hablar de un Derecho administrativo con anterioridad a principios del siglo XIX, en atención a las siguientes razones:

1. La inexistencia de un cuerpo unitario de normas exteriormente obligatorio.

2. La no separación clara entre normas administrativas y normas reguladoras de las relaciones entre los ciudadanos.

Sin embargo, a mi juicio, para afrontar la cuestión conviene partir de la fundamental distinción de Giannini entre:

- Organización administrativa.

- Derecho administrativo, y

- Ciencia de Derecho administrativo ${ }^{18}$.

Todos los ordenamientos jurídicos, como ha sido ya subrayado, incluso los más simples, tienen una estructura u organización administrativa, integrada por instituciones, hechos y actividad de orden administrativo, lo que en el caso de Roma se produce en un nivel de desarrollo semejante a la importancia histórica y al grado de expansión de su comunidad política, y si bien en el plano técnico no existe un cuerpo normativo autónomo, especial y distinto de otros cuerpos normativos, sí parece legítimo utilizar la moderna expresión verbal Derecho administrativo que no pertenece a la tradición jurídica romana, pero sí a la tradición romanística, para referirse al ámbito de experiencia administrativa romana caracterizada por la existencia de un aparato administrativo de compleja estructura integrado por instituciones, hechos y actividad de orden administrativo en el ámbito estatal, provincial y municipal, que intenta resolver la problemática que presenta una sociedad viva y en constante expansión y desarrollo en la que se plantean cuestiones prácticas que continúan vigentes en

18 GIANNINI, Prófilo storico della scienza del diritto administrativo, SS. 1940, pp. $145 \mathrm{y}$ ss. 
el momento actual. En este sentido, Ángel Latorre, en su Valor actual del Derecho Romano, escribe textualmente: «Podemos hablar de una Administración en Roma y de un Derecho administrativo en sentido amplio ${ }^{19}$. En este mismo sentido nos dice Riccobono que en las fuentes clásicas existe una actividad científica de los juristas dirigida a aclarar y sistematizar conceptos e instituciones propias de esta materia $^{20}$. García Camiñas va incluso va allá, al escribir en 1996 que: «... Roma contó con una ciencia del derecho administrativo desde la segunda mitad del siglo II, cuya creación y elaboración es una de las grandes obras del Principado y cuya originalidad podría superar a aquella que es reconocida en temas de derecho privado...» ${ }^{21}$.

Sobre este punto, a mi juicio, cabe señalar que resulta evidente que existió en el derecho romano un conjunto de reguladoras de las competencias y funciones de la administración pública y de las relaciones de ésta con los administrados, que en la experiencia jurídica romana se consideran de ius publicum y que pueden ser denominadas con la moderna expresión de derecho administrativo en atención a su objeto. Lo que no parece que haya existido en Roma, ni referida al Derecho Romano, es una ciencia del Derecho administrativo, en cuanto que no fue la normativa propia de esta materia no fue objeto de especulación teórica general por parte de los juristas romanos, ni ha sido construida por los romanistas ${ }^{22}$, ni tampoco cabe hablar referido al Derecho Romano, por razones obvias, de un Derecho administrativo construido sobre la base de los principios constitucionales propios de la Revolución Francesa Es por ello que, sentadas estas premisas, no parezca razonable cuestionar que el derecho administrativo moderno en sentido técnico, y la ciencia del derecho administrativo, generada a raíz de su existencia, hayan surgido a partir del siglo XIX ${ }^{23}$.

19 LATORRE, Valor actual del Derecho Romano, Barcelona, 1977, pp. 37 y ss.

20 RICCOBONO, Il problema della ricostruzione cit. pp. 665 y ss.

21 GARCÍA CAMIÑAS, Hacia donde camina... cit., pp. 5 y ss.

22 Vid. en este sentido, GIANNINI Diritto Administrativo, ED, XII (Milano 1964), pp. 855 y ss.; A juicio de NOCERA, Il centralismo administrativo del Tardo-Impero cit. p. 603, al igual que a los juristas clásicos les eran desconocidas expresiones como ius poenale o ius criminale, también les era extraña la expresión ius administrativum, por lo que hablar de ciencia del derecho administrativo o incluso de literatura de derecho administrativo aparece legítimo sólo a la luz de un lenguaje más adecuado a nuestras experiencias técnico-científicas.

23 En relación con la influencia de la Revolución Francesa en el Derecho Administrativo, vid. GARCÍA DE ENTERRÍA, Revolución Francesa, Administración contemporánea y formación del sistema municipal francés contemporáneo 198; Id. La Revolución Francesa y la emergencia histórica de la administración contemporánea, en Estudios-Homenaje Pérez Serrano (Madrid, 1959), pp. 202 y ss. 
No se puede negar, sin embargo, a poco que se tenga conocimiento del derecho actual, que hay continuidad histórica en la regulación y en la formulación de los principios informadores de numerosas instituciones administrativas propias del derecho romano y del derecho actual y, en este sentido, voy a proceder a la mención de algunas de las más evidentes, así:

La noción de dominio público,

La distinción romana entre cosas publicas de uso público y cosas públicas patrimonio del estado, que se corresponde con las actuales nociones de bienes demaniales y bienes patrimonio del Estado.

La regulación de las cosas comunes,

La noción de publicatio como acto administrativo por el que una cosa quedaba afectada al uso público,

Las ideas de concesión y autorización administrativa,

La prestación de servicios públicos por entidades privadas o semipúblicas,

El régimen de uso y explotación de vías, minas o aguas públicas,

La contratación de obras públicas con una sociedad privada,

La organización administrativa de las provincias y los municipios,

La progresiva concepción de la función pública y del estatuto de los empleados públicos,

La idea del interés público o común ínsita en las nociones de utilitas publica, utilitas omniun y utilitas universorum,

Los interdictos destinados a la tutela del uso colectivo de las diferentes cosas o lugares de dominio público,

La exigencia de responsabilidades a los empleados públicos por infracciones administrativas,

El orden público y el régimen de policía central, local, funeraria y edilicia,

La opción pública por la restauración de edificios antiguos, frente a su demolición,

La construcción de nuevas edificaciones, en atención a razones de contención del gasto público y de estética urbana,

Las singulares disposiciones arbitradas para remediar la carencia de recursos para construir y mantener en perfecto estado de conservación los edificios públicos,

La implantación de un sistema administrativo creado, en parte, ex novo, para enfrentarse a la nueva realidad que supone el sistema provincial y su expansión por territorio no itálico. 
Las relaciones de la administración local con la administración central,

Los supuestos concretos de expropiación forzosa por causa de utilidad pública, en los que el magistrado competente podía incurrir en responsabilidad frente al ciudadano expropiado si el importe de la expropiación era inferior, de forma manifiesta, al valor real de la cosa expropiada y en responsabilidad ante la propia Administración pública, si otorgaba al civis una indemnización notablemente superior al valor de la cosa expropiada,

Las líneas básicas de una jurisdicción que bien podría denominarse administrativa, en atención a la naturaleza de sus litigios, así : las disputas sobre la consideración de propiedad pública o privada, la ocupación por parte de particulares de campos de cultivo o pastos demaniales, las construcciones ilícitas sobre suelo público, la apropiación indebida del agua pública y , en general, cualquier tipo de litigio nacido de las concesiones administrativas de cosas públicas o de la adjudicación de obras o servicios públicos.

Con el progreso aumentó, en la comunidad política romana, la complejidad de la gestión pública y la dificultad para encauzarla adecuadamente y, si bien encontramos en el Digesto problemas de carácter administrativo, y soluciones a los mismos, que ofrecen una sorprendente modernidad, a nadie le cabe duda que el derecho administrativo y fiscal, continuó desde Roma, su proceso de desarrollo y expansión y, en especial a partir del siglo XIX, se enriqueció y perfeccionó, de forma extraordinaria, si bien las líneas básicas que conforman la administración pública de las ciudades y municipios, como entidades de derecho público, apenas han sufrido modificaciones sustanciales.

\section{C) ÁMBITO DE LA EXPERIENCIA ADMINISTRATIVA ROMANA}

Colonias. Municipios. Provincias. Competencias atribuidas a la Administración Pública. Concesiones administrativas. Gestión de servicios públicos. Tutela de la salud pública. Política fiscal. Policía y Orden público. Aguas, minas y vías públicas. Empleados públicos. Jurisdicción administrativa. El interdicto como providencia administrativa urgente. Eficacia y validez de los actos administrativos. Dominio Público. Utilitas publica. Expropiación forzosa.

En orden a la organización administrativa de los territorios conquistados por Roma: colonias, municipios, provincias y a la conformación jurídico-administrativa de Hispania, cabe señalar que a partir de la conquista de Sicilia, y la expansión por territorio no itálico, 
los romanos se encontraron con nuevos problemas a los que no habían tenido que enfrentarse hasta entonces, por lo que aceptaron en parte el sistema de organización administrativa helenístico, preexistente en diversos territorios y se vieron compelidos a estructurar y regular la nueva realidad administrativa, que se manifestaba, entre otros aspectos, en la relación entre la metrópoli y las nuevas comunidades, mediante la celebración de tratados internacionales, y la creación de municipios y provincias. Con Sicilia y Cerdeña inaugura Roma el sistema provincial, idea que pervive hasta la actualidad, ordenándose la reglamentación administrativa de cada provincia mediante una lex provinciae. El territorio conquistado o anexionado queda afectado al sistema administrativo de las tribus, y las ciudades incorporadas reciben el nombre de municipios o colonias, cuya organización administrativa se regula por ley específica. A partir del Principado la fórmula imperante es el municipio. Sobre la organización administrativa de los municipios y colonias, que reproduce en buena medida la correspondiente a la ciudad de Roma, existe nutrida bibliografía ${ }^{24}$.

Si nos situamos en el ámbito de la península ibérica, cabe subrayar que en el Principado, de forma paulatina, diversas ciudades de la Bética asumieron la condición jurídica de municipios y se integraron, de pleno derecho, en la comunidad política romana, siendo durante los gobiernos de Cesar y Augusto, y los correspondientes a la dinastía de los Flavios, cuando se producen mayores avances en el proceso de romanización. Según Plinio, a finales del primer siglo del Principado, se contaban en la Bética 175 ciudades, muchas de las cuales habían obtenido la condición jurídica de municipios en tiempos de Augusto y otras el status de ciudades titulares del ius latium. La mayor relevancia de entre los municipios romanos, la ostentaban

${ }^{24}$ RICCOBONO, Il problema della ricostruzione cit. 666 ss. IMPALLOMENI, L'inquadrament giuridico delle colonie e dei municipi, cit. pp. 32 y ss. (supra 1 ss.). En relación con la analogía entre la organización administrativa de Roma y la correspondiente a municipios y provincias, cabe mencionar un estudio de X. D'ORS, Lex Flavia 79 , en el que, conforme a los textos examinados, señala como competencias de la curia, la fiscalización de los bienes comunes del municipio; la hacienda municipal, la aprobación de los proyectos de reparación o construcción de obras públicas: carreteras, caminos, canales o cloacas; las materias urbanísticas; destrucción o demolición de edificaciones, etc. Vid en RODRÍGUEZ NEILA, Sociedad y administración local en la Bética romana, Córdoba, 1981. Id. Políticas municipales y gestión pública en la Hispania romana, Polis 15, 2003, pp. 161-197. Id. «Tabullae publicae». Archivos municipales y documentación financiera en las ciudades de la Bética. Dykinson, Madrid, 2005. J. GONZALEZ, Ed. Roma y las Provincias. Realidad administrativa e ideología imperial, Madrid, 1994. LOPEZ BARJA, La provincia transduriana. El edicto del Bierzo, León, 2000, pp. 31-47. 
Corduba y Gades, que se corresponden con las actuales ciudades de Córdoba y Cádiz. Entre los restantes municipios romanos, cabe destacar a Malaca y a Salpensa.

Junto a la progresiva concesión del estatuto municipal a las ciudades, el rasgo más característico de la romanización del territorio peninsular fue la fundación de diversas colonias distinguiéndose entre colonias de ciudadanos romanos, que se correspondían con las de mayor relevancia, y colonias de derecho latino. Fue Italica, en el año 206 a.C., la primera colonia fundada en la Betica, por obra de Publio Cornelio Scipión. Con los emperadores flavios se produce la concesión del ius latium a Hispania ${ }^{25}$.

Un segundo aspecto de la experiencia administrativa romana sería el relativo a sectores correspondientes a la actividad militar, actividad de policía, política económica y financiera, asistencia pública, salud pública (salubritas), enseñanza pública, beneficencia pública, culto público, obras públicas, prestación de servicios públicos por asociaciones privadas, concesiones administrativas, vías y minas públicas, espectáculos públicos en teatros, anfiteatros, hipódromos, etc.

Me voy a detener a continuación en alguno de estos aspectos correspondientes a este segundo ámbito de actividad administrativa.

En Roma era muy frecuente la contratación de una obra pública con una sociedad privada. Su importancia radicaba en que se trataba de auténticos contratos administrativos celebrados entre la Administración y los particulares. Su contenido era muy rico y variado, y tenía como base las leges locationes dictadas primero por los censores y más tarde por el emperador o sus delegados.

Por otra parte, las res publicae y las res universitatis podían ser objeto de uso y disfrute de todos los ciudadanos, salvo en aquellos supuestos de concesión de su uso, disfrute o explotación, con carácter exclusivo o preferente a un particular o una colectividad de personas, por parte del ente público concedente: comunidad política, municipio, provincia o colonia. Se trataba de un acto de potestad discrecional de la Administración central o local, que se utilizó con carácter habitual desde mediados de la República hasta la época justinianea, y que teniendo una finalidad básicamente fiscal o recaudatoria de rentas constituyó una de las principales fuentes de ingresos para los sujetos concedentes.

25 Vid. al respecto, con carácter general, sobre la latinidad en Hispania, en Bravo Bosch, El largo camino de los hispani hacia la ciudadanía. Dykinson, Madrid, 2008. 
Junto a este tipo de concesión sobre cosas de dominio público, entre las que cabría destacar: el ager publicus, la autorización para edificar en lugares públicos, la explotación de minas o salinas públicas, puentes públicos (cuya utilización exigía el pago del correspondiente $\mathrm{y}$ «moderno» peaje), vías de comunicación, derecho exclusivo o preferente de pesca de determinados peces como atunes o salmones, derivaciones de agua pública para usos particulares, etc., se utilizaron y regularon, al propio tiempo, las concesiones de prestación de servicios públicos como vigilancia antiincendios, baños públicos, suministros públicos, cobro de impuestos, etc., y las concesiones de contratación de una obra pública, sistema este último por el que se hicieron realidad numerosos palacios, faros, puertos, cárceles, etc.

Se plantea asimismo en las fuentes el controvertido tema relativo a la posible autorización, a particulares o colectividades, para construir edificaciones en el mar o en su litoral.

No hay en Derecho Romano una ley que regule con carácter global y unitario la concesión administrativa con la excepción de una ley general referida a las concesiones mineras: lex metallis dicta ${ }^{26}$, por lo que hay que acudir a las leyes agrarias, leges locationes de los censores, leyes municipales, edictos sobre cosas públicas, inscripciones epigráficas, etc., para conocer y analizar las particulares y múltiples concesiones. Sin embargo, sí se pueden señalar una serie de rasgos comunes a todos los supuestos que reflejan numerosas coincidencias y que serían los siguientes: si bien la terminología no es unitaria sí se utilizan con profusión los términos concedere y permittere; está previsto un amplio elenco de interdictos dirigidos a la defensa de los concesionarios públicos; existe un riguroso y formal procedimiento previo a la concesión; los concesionarios se adhieren, en su caso, a unos minuciosos pliegos de condiciones, en los que se recogen aspectos referidos al carácter temporal o perpetuo de la concesión, las facultades y obligaciones del concedente y concesionario, las modalidades de pago del canon o vectigal, las eventuales garantías a prestar por el concesionario y los controles a realizar por parte del ente público concedente.

${ }^{26}$ Sobre la utilización de los términos concesión, derechos de explotación o concesiones de explotación, en expresión de A. D'ORS referidas a la concesión minera, vid., VERGARA, Contribución a la historia del Derecho minero, Revista de Estudios Histórico-Jurídicos 12 (Valparaíso, 1987-88), pp. 24 y ss. Sobre las tablas de bronce de Vipasca y la lex metallis dicta puede consultarse, en estos, los siguientes estudios: D'ORS, Sobre la Lex Metalli Vipascensis, Iura (1951) pp. 127 y ss.; Id. Epigrafía jurídica de la España Romana (Madrid, 1953), pp. 71 y ss.; GIUFFRE, Le Lois del Romains (Napoli, 1977), pp. 78 y ss.; VERGARA, Contribución a la historia cit., pp. 23 y ss. 
Tanto la Administración central del Estado o populus romanus como los entes locales menores - ciudades, municipios y coloniastuvieron competencia para conceder los bienes de dominio público. En ambas administraciones resulta significativo el amplio número de magistrados y funcionarios entre cuyas competencias se encontraba la de conceder los bienes públicos, pues si bien esta facultad fue principalmente ejercida por los censores y los distintos curatores de las obras públicas, tenemos noticia de concesiones otorgadas por el Príncipe, los cónsules, los pretores, el Senado, el curator rei publicae, y por otros magistrados municipales menores como los quatuorviri, los duoviri o los mismos ediles ${ }^{27}$.

Sobre prestación de servicios públicos por sociedades de particulares a través de la figura de la concesión, tiene escrito, MURGA que: «fue algo ordinario dentro de la variada administración municipal romana que el servicio público no lo ofreciera directamente la curia municipal sino que se prestara a través de un contratista - redemptor - cuya actuación debía ser siempre conforme a la lex locationis. No es raro encontrar en el Digesto frecuentes referencias a los más variados servicios públicos cedidos en arrendamiento a un redemptor, debiendo en todo caso el concesionario sujetarse al contrato con un planteamiento absolutamente privatístico... ${ }^{28}$. En relación con la prestación de servicios públicos por sociedades privadas o semipúblicas cabe asimismo señalar que si bien se remontan a la época monárquica las asociaciones de artesanos mercaderes, es en el marco de la intensa vida societaria republicana, caracterizada por el principio de la libertad contractual y asociativa, donde comienza a configurarse la figura de la prestación de servicios públicos, o la realización de obras públicas por parte de particulares o de sociedades privadas ya existentes o creadas ad hoc, para cumplir la finalidad con-

27 Vid. en general, como visión del conjunto, sobre concesiones administrativas, CASTÁN PÉREZ-GÓMEZ Régimen jurídico de las concesiones administrativas en Derecho Romano (Madrid 1996). En relación con el contenido de la prestación de pública utilidad realizada por la asociación privada concesionaria, destaca RICCOBONO Il problema cit. 669, que tanto puede tratarse del ejercicio de una actividad técnico-jurídica a favor de la administración pública (por ej. la recaudación de impuestos por las societates publicanorum), como de actividades materiales a favor de la colectividad (por ej. transportes, vigilancia contra incendios, aprovisionamiento, etc.); BLANCH NOUGUÉS, J. M., La concesión de obras públicas y su financiación en el Derecho Romano, RGDR Iustel, 8, junio 2007.

28 MURGA, la popularidad de las acciones en las leyes municipales de la Betica RIDA, 1991, pp. 240 y ss. En D. 19, 2, 60, 8 se recoge un fragmento de Labeón en el que se regula la concesión de un puente a un particular, el cual puede exigir el correspondiente portorium o peaje a todo el que pretendiese pasar por el puente objeto de la concesión. 
venida. En otras ocasiones, era la propia Administración la que prestaba el servicio público correspondiente, que en el caso de nueva creación implicaba o bien la atribución de empleados públicos a las nuevas necesidades sociales o bien la creación de cargos y empleados ex novo para el desempeño de las nuevas funciones.

La gestión de servicios o la construcción de obras públicas así configuradas, suponía una serie de ventajas para la Administración, consistentes tanto en el ahorro de los sueldos de empleados o funcionarios, como en las retribuciones recibidas por adelantado, al propio tiempo que escasos riesgos en atención a las cautelas y garantías que los particulares o sociedades concesionarias debían prestar, como hipotecas sobre bienes determinados de los arrendatarios del servicio o garantías personales. Por otra parte, la principal obligación de la Administración pública consistía en asumir las labores de vigilancia y control tendentes a una adecuada prestación del servicio o ejecución de la obra contratada.

La adjudicación de la obra o servicio, se hacía a través de la fórmula de una subasta pública dirigida por los censores, cuestores, curatores operum publicorum, o procuradores especiales, según las épocas, en la que se exponían unos pliegos de condiciones, con cláusulas precisas sobre derechos y obligaciones de las partes, denominadas leges censoriae o leges locationis. La subasta concluía con la aceptación de la mejor oferta de entre aquéllas que, con la capacidad de obrar requerida, concurrían a la licitación. El plazo de concesión o arrendamiento solía ser de 4 ó 5 años ${ }^{29}$.

La regulación de las competencias de la Administración en materias como el orden público, la disciplina del tráfico, la policía ciudadana, policía de los mercados, atribución a los gobernadores de las competencias en materia de policía, etc., es objeto de una precisa regulación, de manera especial en época de Justiniano, que procede a una reorganización administrativa que no llegó a concretarse en profundidad en los años posteriores ${ }^{30}$.

${ }^{29}$ Vid en este sentido en PENDÓN MELÉNDEZ, Esther, Régimen jurídico de la prestación de servicios públicos en Derecho Romano, prologo A. Fernández de Buján, pp. 19-23, Cádiz, 2002.

${ }^{30}$ Vid. IMPALLOMENI, Agentes in rebus, en Scritti giuridici vari (Padova, 1996) pp. 9 y ss.; PULIATTI, Richerce sulla legislazione regionale di Giustiniano. Lo statuto civile e l'ordinamento militare della prefettura africana (Milano, 1980). En el año 2003 se leyó en la UAM una tesis doctoral, bajo mi dirección, bajo el título Policía y orden público en Derecho Romano por Aurora Fernández Rosaenz, en prensa en la Colección de Monografías de Derecho Administrativo Romano de la Editorial Dykinson. 
En materia de tutela de la salud pública (salubritas), cabe afirmar que se contiene en el libro 43 del Digesto la regulación de los interdictos dirigidos a impedir el deterioro de los vertederos y cloacas públicas y privadas. Se trataba de interdictos restitutorios mediante los cuales la autoridad administrativa garantiza el perfecto funcionamiento de las cloacas privadas ordenando a sus poseedores la purgatio y la refectio, a fin de evitar el peligro de enfermedad y pestilencia a las poblaciones. Asimismo está regulado de modo preciso en el libro 43 del Digesto, el funcionamiento de las cloacas públicas, atribuyéndose a la autoridad administrativa el deber de realizar las obras dirigidas a evitar riesgos para la higiene y la salud pública, lo que se concretó en una regulación de lo que, con terminología moderna, podría denominarse protección del medio ambiente.

Una obra fundamental para conocer el sistema de abastecimiento de agua en Roma, que constituye, por otra parte, una de las manifestaciones más originales del arte de construcción romana, es el estudio de Frontino sobre acueductos de la ciudad de Roma. Es una obra de tipo técnico, escrita por un alto funcionario e ingeniero, en la que se estudia la distribución, protección, mantenimiento y legislación en materia de abastecimiento de aguas ${ }^{31}$.

Un administrativista actual, GALLEGO ANABITARTE, escribió a propósito de un amplio y colectivo estudio sobre la Ley de Aguas de 1985: "Pese a la superior complejidad del Derecho público actual, en relación con otras épocas, a la hora de teorizar, definir y clasificar el material jurídico positivo, vuelven a surgir problemas e instituciones seculares que nacieron en el Derecho romano: así, por ejemplo, en la materia que nos afecta, es un hecho extraordinario pero el Derecho romano de aguas ha estado y está presente en todos los estudios de aguas del Derecho Occidental. El tronco común del que salen el actual Derecho francés, anglosajón, alemán y español es el Derecho romano» ${ }^{32}$.

En relación con las aguas públicas en Derecho Romano, materia sobre la que la producción científica es muy amplia, cabe decir como idea básica, si bien referida sólo a los ríos que, según un conocido texto de Ulpiano, es la perennidad la circunstancia más característica

31 Existe una edición bilingüe, en español, de la obra de Frontino, Los acueductos de Roma, con comentarios de GONZÁLEZ ROLDÁN (Madrid, 1985). En De aqueductu urbis Romae nos dice Frontino en 1.1 que el cargo de administrador de las aguas en Roma no sólo afecta al provecho sino también a la sanidad e incluso a la seguridad de la Urbe (...ad usum tum ad salubritatem atque etiam ad securitatem urbis pertinens ...).

32 GALlEGO ANABITARTE, MENENDEZ REXACH, DÍAZ LEMA, El Derecho de Aguas en España cit. 
de los ríos públicos ${ }^{33}$. Además de los ríos perennes, tenían la consideración de públicos aquellos que así hubiesen sido considerados desde tiempo inmemorial, o bien aquellos que por sus especiales circunstancias geográficas o singular valoración social, tuvieren reconocida tal cualidad $^{34}$. Aspectos concretos relativos a ríos públicos, dársenas, puertos y costas han sido estudiados de manera particularizada, entre otros muchos autores, por IMPALLOMENI ${ }^{35}$ y por Alburquerque ${ }^{36}$.

El estudio de la titularidad de las aguas superficiales continentales, constituyó el objeto de la Tesis Doctoral de Gerez Kraemer en el año 2000 y la base de su monografía sobre El derecho de aguas en Roma, publicada en $2005^{37}$.

33 D. 43, 12, 1, 2 (Ulp. 68 ad ed.) ...publicum flumen esse Cassius definit, quod perenne sit: haec sentencia Cassi, quam et Celsus probat, videtur esse probebilis.

${ }_{34}$ D.43, 12,1,1 (Ulp. 68 ad ed.) ...flumen a uvo magnitudine discernendum est, aut existimatione circumcolentium.... vid. Asimismo en GEREZ KRAEMER, Régimen jurídico de las aguas en Derecho Romano. Prólogo A. Fernández de Buján. Dykinson. Madrid, 2008.

35 IMPALLOMENI, Le rade, i porti, le darsene e le opere a terra, en Scritti cit., pp. 583 y ss.

${ }_{36}$ Alburquerque, Reflexiones en tema de navegación y reparación de las orillas en los ríos públicos, RGDR, Iustel, n. 5, 2005; Id. Interdictum ne quid in flumine publico ripave eius fiat, quo peius navigetur (D. 43,12,1 pr.), «SDHI», 71, 2005, pp. 193-269.

37 GEREZ KRAEMER, El derecho de aguas en Roma. Prólogo de A. Fernández de Buján. Madrid, 2008. El problema de la titularidad de las aguas es afrontado por Gerez desde la perspectiva de sus distintas manifestaciones, dividiéndolas en pluviales, manantiales, estancadas y corrientes. Sin embargo, antes de entrar en el examen de su régimen jurídico, el A. procede a la identificación de todas las voces con las que, en cada caso, las aguas son designadas, aquae pluviae, aqua viva, aqua profluens, lacus, stagnum, palus, fluvius, flumen, rivus etc., a fin de delimitar, de la forma más precisa posible, su verdadero alcance y significado. El análisis semántico de los términos supone una valiosa ayuda de la que el A. se vale para enfrentarse a cuestiones objeto de debate doctrinal como: la disputada polémica del aqua profluens, el concepto de aqua pluviae, la distinción entre los lacus y los stagna, o el controvertido texto ulpinianeo, D. 43.12.1 y 2, que separa los rivi de los flumina.

Una vez analizado el alcance de los principales vocablos con los que los juristas romanos y los textos legales designaron las aguas, el autor se adentra —en relación con cada una de los diversos tipos- en el problema de su régimen jurídico y más concretamente de su dominio. En este punto cabe resaltar que el A. se pronuncia y avanza una solución, en cada caso, en las numerosas e intrincadas controversias que históricamente han suscitado las fuentes. De entre ellas, cabría destacar: a)Su interpretación de la tan famosa y controvertida expresión ulpianea videtur esse probabilis referida a los cauces más importantes,b) La solución que se ofrece a la antiquísima (tanto como la propia Compilación de Justiniano) supuesta contradicción relativa a la titularidad y régimen jurídico de los flumina, en cuyo origen se encuentra el texto de Ulpiano contenido en D. 43.12.1.3 y los correspondientes de las Instituciones de Marciano entre D.1.8.4.1 (Marc. 3 Inst.) y Justiniano, I.2.1.2. .c) El análisis del régimen jurídico de las aguas estancadas, stagnantes y d )El alcance y finalidad del requisito del caput aquae. 
A la conexión entre la normativa romana en materia de aguas, y la legislación española al respecto, en especial en relación con la Ley de Aguas de 1866, se han referido, entre otros autores, Schulten, MartínRetortillo y Gallego Anabitarte, quienes han resaltado asimismo la escasa incidencia de las disposiciones del derecho árabe en el ámbito del derecho histórico español. Los Ordenamientos Jurídicos Modernos son, y la investigación en materia de aguas públicas es una buena prueba de ello, el resultado de sucesivas experiencias históricas que deberán ser tenidas necesariamente en cuenta por los estudiosos si aspiran a la construcción de una dogmática, en el sentido conceptual del término, de base científica. Al propio tiempo, las soluciones jurídicas a los problemas que se plantean, nacen en un contexto socio-político y económico determinado, que necesariamente debe ser tenido en cuenta a la hora de analizar la causa y el objeto perseguido en la correspondiente regulación.

Si bien la temática relativa a las aguas carece en las fuentes romanas de una sede unitaria ${ }^{38}$, el análisis de las diversas fuentes específicas destaca por su notable coherencia. La dispersión legislativa en la materia se prolonga en el derecho histórico español hasta la publicación de la Ley de Aguas de 1866, y se mantiene en sede del Código Civil de 1898, que se ocupa de las aguas públicas en el contexto de las clases de cosas, las servidumbres y el régimen de la propiedad, desde dos perspectivas distintas, tal y como sucedía en el antiguo derecho romano de las XII Tablas, de mediados del siglo V a.C., en el que las aguas se enmarcaban en sede de la regulación de los bienes susceptibles de aprovechamiento, Tabla $7.8 \mathrm{~b}$ y como fuente de daños, Tabla $7,8^{\mathrm{a}}$.

En materia de minas públicas cabe destacar la Tesis Doctoral (publicada) dirigida por Âlvaro D'ORS a VERGARA bajo el título «Reconstrucción histórica y dogmática del Derecho Minero». Destaca este autor que en el año 320 de nuestra era, se aprueba a través de una ley, que se ha calificado de revolucionaria, un principio que per-

38 Vid. en materia de aguas, en Gérez Kraemer, y la bibliografía allí citada, en El requisito de la perpetua causa, RIDA 1998, T.XIV, pp. 229-242; Id., «Titularidad y aprovechamiento de las aguas continentales en la tradición jurídica española», recogido en la obra Derecho Administrativo Histórico. Dirección A. Fernández de Buján. Xunta de Galicia, Santiago de Compostela 2005; Id., Nota a propósito del requisito del caput aquae. RGDR, Iustel, n. 2, 2004, pp. 1-11; Id., Una interpretación de la famosa expresión ulpinianea videtur esse probabilis en D. 43.12.1.3 RGDR., n. 3, 2004; Id., Una nota aclaratoria acerca de la célebre contradicción entre D. 1.8.4.1 e I. 2.1.2. RGDR, n. 5, 2005; La protección interdictal del dominio público hidráulico: una primera aproximación. RGDR, Iustel, n. 7, dcbr 2006, pp. 1-22. 
duraría para siempre en los regímenes jurídicos de la minería: la facultad de buscar y cavar en tierras ajenas. Ello se debe al cambio de la idea tradicional de que el propietario del suelo lo es asimismo, sin limitaciones, del subsuelo. Irrumpe en la legislación la idea de que el subsuelo es de dominio público, sin detrimento por ello de las facultades y compensaciones que se reconocen al respecto al dueño del suelo. El estudio del régimen jurídico de la minería pública, que constituyó una importante fuente de ingresos para el Erario y con posterioridad para el Fisco en Roma, y de la concesión administrativa minera, que se requiere, en todo caso, para iniciar la exploración o explotación de minas o canteras, pone de manifiesto la minuciosidad y el tecnicismo con que se abordó esta cuestión en el Derecho Romano. Para Vergara en el Derecho provincial surgen una serie de valores y principios que desarrollados en el Código Teodosiano y en el Código de Justiniano constituyen la base del actual Derecho minerario moderno ${ }^{39}$. Aborda RODRÍGUEZ ENNES, con carácter específico, en reciente monografía, la explotación minera de Gallaecia mediante una descripción minuciosa de las técnicas empleadas partiendo fundamentalmente de la Naturalis Historia pliniana, pero sin descuidar los testimonios epigráficos e incluso arqueológicos.

En punto al marco jurídico, la situación es especialmente complicada por la colisión que se plantea -incluso en nuestros días- entre la titularidad del suelo y el interés estatal en la explotación de la riqueza del subsuelo. Con todo, en Gallaecia, dado su carácter de territorio conquistado, el suelo era ager publicus $y$, por ende, propiedad del Populus Romanus, con lo que no se planteaba el aludido conflicto entre el derecho individual de propiedad y el interés estatal. Por lo que hace a la administración, RODRÍGUEZ-ENNES considera que -en época republicana- las fuentes atestiguan sin ambages la adjudicación de la misma a las societates publicanorum mediante locationes. Así las cosas, los publicani contrataban la explotación de los vectigalia publica populi romiani, que los censores conferían en locatio corrductio mediante subasta. Como contratistas públicos, los adjudicatarios quedaban sometidos a las cláusulas dictadas por los censores. La era imperial se caracteriza por la escasez de fuentes al respecto. La reorganización provincial de Augusto va a motivar que los yacimientos minerales galaicos pasen al Fiscus Caesaris y, en consecuencia, sean administrados por un procurador metallorum que

39 VERGARA, Contribución a la historia..., cit., pp. 13 y ss.; Id. Formulación de principios para el derecho minero, Revista de Derecho Público 41 (Santiago de Chile); id. Reconstrucción histórica y dogmática del derecho minero (Universidad de Navarra), Pamplona, 1988. 
gobernaba exclusivamente el distrito minero en el que tenía jurisdicción plena, como queda muy claro en las Leyes de Vipasca ${ }^{40}$.

La regulación de las vías públicas en Derecho Romano, objeto de un reciente estudio de Ponte Arrebola, resulta muy precisa y comprensiva de los más diversos aspectos, como por ejemplo:

- Las diversas clasificaciones atendiendo a distintos criterios, como la longitud (via, actus, iter o semi-iter), o la titularidad del suelo (públicas, agrarias o vecinales). La compleja realidad de los caminos o calzadas conocidos con la denominación de viae militares.

- La procedencia de los fondos utilizados para la construcción de la vía pública: calzadas, caminos y calles.

- El conjunto de obligaciones y, en ocasiones, privilegios, que traía consigo la presencia o vecindad de una vía pública.

- La regulación de los trabajos, de conservación y reparación de las rutas. El personal, magistrados, empleados y funcionarios, al servicio de la guarda y custodia de las vías.

- La regulación de la mano de obra utilizada para la construcción: soldados, contratados a jornal, vecinos de los pueblos limítrofes, penados condenados a trabajos forzados, etcétera.

- La expropiación forzosa de terrenos para la construcción de las calzadas o vías públicas.

- El régimen fiscal de las vías públicas. Las cargas impuestas a las personas o entidades beneficiadas. Inmunidad fiscal y bonificaciones.

- El elenco de cuestiones físicas, relacionadas con las vías: estructura, materiales empleados, trazado, zonas o elementos accesorios, etcétera.

- La adjudicación, por concesión administrativa, de la construcción de vías públicas a sociedades de particulares. El recurso a la locatio-conductio, cuando se procede a la adjudicación de las labores de alzamiento o sostenimiento de los caminos.

40 RODRÍGUEZ ENNES, Gallaecia: romanización y ordenación del territorio, prólogo A. Fernández de Buján, Madrid 2005; Id., Minería romana, minería castellana, minería de la América colonial española: Historia de un tracto sucesivo, «RGDR» Iustel, 7, diciembre 2006; Bravo Bosch, Derecho Privado y Derecho Público en relación con los yacimientos mineros de Gallaecia, RGDR, Iustel, 11, diciembre, 2008. 
- Las acciones a favor de los colonos frente a aquellos que alteren las calles o sus límites. El interdicto como principal instrumento en este marco de actuación.

- La ordenación, medición y planificación geométrica de las ciudades. ${ }^{41}$.

En materia de política financiera, cabe destacar la pervivencia de conceptos e ideas conocidas y desarrolladas en Derecho Romano que continúan vigentes en la legislación actual, como Erario (aerarium), Fisco (fiscus), fraude fiscal (fraus fisci), tributo (tributum), abogado del fisco (advocatus fisci ${ }^{42}$ ), decomiso (commissum ${ }^{43}$ ), etc., e ideas como la distinción entre impuestos directos e indirectos, o como señala recientemente JUAN M. BLANCH, la división de la tierra en clases a efectos de tributación, la concepción dogmática de la obligación tributaria como gravamen o carga, la equidad en la estimación, la posibilidad de pedir la rectificación del censo, la proporcionalidad y generalidad como principios impositivos básicos, la reserva de ley, la equidad como base de las exenciones, el error en la declaración, etc. ${ }^{44}$.

En el campo del derecho fiscal romano, ius fisci, se asimismo la utilización de distintos instrumentos de derecho financiero que son objeto de regulación en las fuentes romanas y permanecen en vigor con el paso de los siglos, como expedientes de política fiscal, si bien

${ }^{41}$ Vid. en PONTE ARREBOLA, Régimen jurídico de las vías públicas en Derecho Romano, Prólogo A. Fernández de Buján, en prensa Madrid, 2005; PONTE ARREBOLA, Normas romanas y vías públicas, "Xornadas e Seminarios: Derecho Administrativo Histórico», 1, 2005, pp. 317-354 ; Id. La búsqueda de la seguridad y el orden en las calles de Roma, "Anuario da Facultade de Dereito da Universidade da Coruña», 9, 2005, pp. 723-738; Id. Guardianes y custodios de las calzadas romanas: el curator viarum, AA.VV., «Personalidad y capacidad jurídicas. 74 contribuciones con motivo del XXV aniversario de la Facultad de Derecho de Córdoba», II, Universidad de Córdoba, 2005, pp. 1153-1166; ID. La defensa de las vías públicas romanas. Interditos especiales para la protección del disfrute de las viae publicae, RGDR Iustel, 9, diciembre 2007.

Id. MURGA, La popularidad de las acciones, cit., p. 276 en el capítulo 104 de la Lex Irnitana se ofrece a cualquier colono una acción popular contra todos aquellos que intentaren alterar el trazado de las calles, límites y monumentos.

${ }^{42}$ AGUDO RUIZ, A., El advocatus fisci en Derecho Romano, Madrid, 2006.Id. Los advocati fisci en la legislación de Anastasio, en «RGDR» Iustel, 6, junio 2006.

${ }^{43}$ Vid. al respecto en Zamora Manzano, Algunos aspectos sobre el régimen fiscal aduanero en el Derecho Romano. Dykinson, Madrid, 2009.

${ }_{44}$ BLANCH, Principios básicos de la justicia tributaria en la fiscalidad romana, Revista española de Derecho Financiero 1997; LUZZATTO, s.v. Imposta, munera, stipendium, tributum, y vectigalia del NNDDI; acerca de la responsabilidad solidaria de las decisiones en los municipios, por la recaudación de impuestos vid. IMPALLOMENi, L'inquadramento giuridico delle colonie e dei municipi cit. p.36. 
adolecen, muchos de ellos, de la ausencia de un estudio en profundidad por parte de la doctrina ${ }^{45}$.

Cabría citar, al respecto:

- Los índices de inflación ${ }^{46}$.

- Los flujos monetarios ${ }^{47}$.

- La devaluación de la moneda ${ }^{48}$.

- La creación de una moneda única y un mercado común, sin fronteras ${ }^{49}$.

- Los modelos privado y público de financiación de las obras públicas $^{50}$.

- La reducción o el aumento de los gastos generales en atención a la coyuntura económica ${ }^{51}$.

- El análisis contable, por parte de los empleados públicos responsables, de los gastos e ingresos públicos, con la finalidad de adaptar las correspondientes partidas contables a las profundas transformaciones que se producen en la sociedad y en la economía de su tiempo ${ }^{52}$.

45 Vid., con carácter general, en GUARINI, La finanza del popolo romano. Trattato storico-legale (Napoli 1841); DI RENZO, Il sistema cit.; CASAL BRAVO, El erario y el fiscus en la Roma de Augusto, en RDF y HP 13 (1954); La finanza antica (Milano, 1955); FESTO, Lineamenti dell evoluzione tributaria nel mondo antico, edt. Lindsay (1956); DUNCAN-JONES, The economy of the Roman Empire. Quantitative Studies (Cambridge, 1974); CHASTAGNOL, Problémes fiscaux du Bas-Empire, en Points de vue sur la fiscalité Antique (París, 1979), pp. 127 ss.; MASI, L'amministrazione finanziaria, en Lineamenti di storia del diritto romano, bajo la dirección de Talamancam (Milano, 1989); CERAMI, Aspetti cit.; GARCÍA GARRIDO, El comercio, los negocios y las finanzas en el mundo antiguo (Madrid, 2001); SCHEIDEL, The size of the economy and the distribution of income in the Roman Empire, "Princeton/Stanford Working Papers in Classical», 5, 2009; Id. Economy and quality of life in the Roman world, "Princeton/Stanford Working Papers in Classical», 5, 2009.

46 Vid. en BLAZQUEZ, Inflación, subida galopante de los precios y devaluaciones de la moneda en el final del mundo antiguo, en Jano 141 (1974), pp. 113 y ss.

47 Vid. en MINAUD, La comptabilité á Rome (Lausanne, 2005).

48 DE LAET, Une devaluation dans l'Antiquité: la réforme monétaire de l'année 64 ap. J.Chr, en Revue de la Banque VII (París, 1943).

49 Vid. en DE SANCTIS, Storia del romani II (Florencia, 1967).

${ }^{50}$ Vid. en MALAVÉ OSUNA, Régimen jurídico financiero cit.; Id.

51 Vid. en MILAZZO, La realizzazione delle opere pubbliche in Roma arcaica e republicana. Munera e ultro tributa (Napoli, 1993); ROBLES VELASCO, Notas sobre las crisis económicas en el Imperio Romano: entre la libre iniciativa y el intervencionismo, en RGDR. (www.iustel.com) 12 (2009) pp. 1-13.

52 Vid. al respecto en: HUMBERT, Saggio sulle finanze e sulla contabilità pubblica presso i romani (Bologna, 1977); GIMÉNEZ BARRIOCANAL, La actividad cit.; MINAUD, La comptabilité cit. 
— La contención y el control del gasto público ${ }^{53}$.

- La prestación de servicios públicos por parte de sociedades privadas $^{54}$.

- El ensayo de medidas de presión fiscal o de minoración en la imposición, frente a la crisis económica ${ }^{55}$.

- La inversión de capitales con el objetivo de evitar la excesiva tesorización de las arcas públicas, o de fomento del empleo ${ }^{56}$.

- La prohibición de exportar determinadas armas, oro o productos básicos que fortalezcan a los pueblos adversarios del romano $^{57}$

- Las franquicias o exenciones aduaneras en relación con los productos de uso propio, res ad usum propium o con mercancías destinadas a tareas agrícolas ${ }^{58}$.

- Los mecanismos de control del contrabando aduanero y el comiso fiscal ${ }^{59}$.

- La opción pública por la restauración de edificios antiguos, frente a su demolición ${ }^{60}$.

53 Vid. en CERAMI, Il controllo finanziario in Diritto romano. Riflessione metodologique e profilo storico, en Studi Scherillo (Milano 1972), pp. 767-802.

54 Vid. en PENDÓN MELÉNDEZ, Régimen jurídico cit.; CASTÁN PÉREZ, Régimen jurídico cit.. En relación con las garantías reales y personales que debían prestarse por las personas físicas o jurídicas que contrataban con la Administración pública romana los distintos tipos de concesiones, obras públicas, edificios públicos, derivaciones de agua, salinas o minas públicas etc., vid. en MENTXAKA, Algunas consideraciones en torno a las concesiones administrativas y sus garantías: capítulos 63-65 de la Lex Malacitana, en Leyes municipales en Hispania (Málaga, 2001), pp. 71 y ss.

55 Vid en CHASTAGNOL, Problémes fiscaux cit., pp. 127 y ss.

56 Vid. en BODEI, Lavori pubblici e occupazionali nell'antichità classica (Bologna, 1973), donde la autora relaciona el denominado evergetismo con condicionamientos económicos que hacen necesaria la inversión de capitales con la doble finalidad de evitar el exceso de stocks dinerarios y de propiciar mecanismos sociales de fomento del empleo.

57 Vid. al respecto en C. 4. 41.1, C. 4.42.2 y C. 4.63.2.

58 Vid. en ZAMORA, Algunos aspectos cit.

59 Vid. en: KLIGENBERG, Commissum, der Verfall nichtdeklarierter Sachen in römischen Zollrecht (Graz, 1977); PINO ABAD, La pena de confiscación de bienes en el derecho histórico español (Córdoba, 1999). Sobre el comiso por defraudación en la Lex Portus Asiae, vid. en: CARRELLI, Alcune osservazioni sul portorium Asiae, en Studi Ellenistiche 8 (1996) y en SPAGNUOLO VIGORITA, Lex Portus Asiae, un nuovo documento sull'appalto delle imposte con la pubblica amministrazione nel'experienza storico-giuridica (Napoli, 1997).

${ }_{60}$ Vid en KUNDEREWICZ, La protection des monuments d'architecture antique dans le Code Theodosienne, en Studi in onore di Volterra 4 (1971) y en, ALBURQUERQUE, Protección de bienes de dominio público: Experiencia administrativa romana, en Derecho Administrativo Histórico (Santiago de Compostela 2005), pp. 17-77. 
- La construcción de nuevas edificaciones, en atención a razones de contención del gasto público y de estética urbana ${ }^{61}$.

- Las singulares disposiciones arbitradas para remediar la carencia de recursos para construir y mantener en perfecto estado de conservación los edificios públicos ${ }^{62}$.

Con los expedientes de política fiscal mencionados, se trataba de abordar y dar soluciones a problemas propios de la época, que se han continuado planteando, desde entonces, de forma recurrente, a lo largo de la historia, así, entre otros: la crisis económica, la inflación producida por la devaluación de la moneda, la crisis demográfica y el subsiguiente retroceso en la industria y el comercio, o la focalización del gasto público hacia necesidades militares.

En relación con los Principios informadores del Sistema Tributario romano cabe señalar que en los textos contenidos en las fuentes romanas, se recogen reflexiones jurisprudenciales que asumidas, en gran medida, por la legislación del principado y del imperio, se reflejan en una serie de reglas y principios de justicia tributaria que, formulados, por regla general, en relación con casos concretos, mitigan y limitan el mero afán recaudatorio del ius fiscale, y constituyen el germen, en unos casos, y la expresión literal, en otros supuestos, de determinados principios informadores del actual sistema financiero español ${ }^{63}$.

Cabría afirmar, en definitiva al respecto, que el valor permanente y la actualidad de las grandes cuestiones que se han planteado en el marco del ius fiscale en la comunidad política romana, constituyen una prueba del fundamento romanístico sobre el que se asienta el actual derecho fiscal europeo, lo que no es, por otra parte, sino una manifestación de la historicidad del derecho también en este sector del Ordenamiento Jurídico, y de su conformación como un agregado lógico e histórico de experiencias colectivas. Y no se trata, con todo ello, de reconstruir el derecho fiscal romano como un apriorismo

61 Vid. en TRISCIUOGLIO, Sarta tecta, Ultr otributa, opus publicum faciendum locare. Sugli appalti relativi alle opere pubbliche nell'etá republicana e augustea (Napoli, 1998); MALAVÉ OSUNA, Régimen jurídico financiero cit. ; JIMÉNEZ SALCEDO, M. ${ }^{a}$ C., Notas sobre urbanismo en Derecho Romano, «RGDR» (www.iustel.com), 5, diciembre 2005.

${ }^{62}$ Vid. en BODEI, Lavori pubblici cit.; MALAVÉ OSUNA, Régimen jurídico financiero cit.; Id. MALAVÉ OSUNA, B., Las contribuciones forzosas de los particulares a las obras públicas, RGDR. Iustel, 4, junio 2005.

63 Vid. al respecto en Fernández de Buján, A. Ius fiscale: Instrumentos de política financiera y Principios informadores del sistema tributario romano, Estudios en Homenaje al Prof. Rodriguez Bereijo, Tompson- Civitas, 2010. 
científico por su interés histórico para el actual derecho fiscal, es que la conexión entre el derecho romano y el derecho vigente existe, en numerosos aspectos, en esta rama del conocimiento jurídico, lo que se manifiesta en una continuidad histórica en el planteamiento de problemas y en el arbitrio de soluciones, en materia fiscal y de hacienda pública ${ }^{64}$, que todavía hoy sorprenden por su modernidad y constituyen una útil herramienta de explicación, en determinados aspectos, de la realidad del fenómeno impositivo en el momento actual ${ }^{65}$.

En materia de policía y orden interno en Roma, se produce una evolución desde las primeras manifestaciones de policía organizada, a la que se atribuye el control de la seguridad y el orden interno en la República, hasta el burocratizado y especializado servicio de seguridad interno y externo en el Bajo Imperio.

El orden interno en el territorio de la comunidad política romana abarca al propio tiempo la seguridad personal de los ciudadanos, cuya salvaguarda se atribuye a la policía urbana, como la seguridad del Estado, de la que se responsabiliza un cada vez más perfeccionado servicio de espionaje que, vinculado al ejército durante siglos, acaba desvinculándose de éste, para configurarse como un organismo autónomo, dependiente del poder político. Las convulsiones vividas en Roma en el último siglo de la República, la ausencia de su previsión y el fracaso de los medios utilizados para contrarrestarles, hicieron necesaria la intervención de las legiones, así como la determinación primero de César, y con posterioridad de Augusto, de crear un cuerpo de policía altamente cualificado, especializado y dotado de los

64 A la necesidad asimismo de abordar la fiscalidad romana, desde un punto de vista dogmático, lo que no supone, en modo alguno, «hacer de buceador de la historia, zambulléndose en las profundidades insondables del pasado, para emerger con un precedente en la mano en materia fiscal», se refiere BLANCH, Juan M., en Principios básicos de justicia tributaria en la fiscalidad romana, en Revista de Derecho Financiero y Hacienda Pública XLVIII 247 (Madrid, 1998), pp. 55 y ss., y en Ordenación sistemática del derecho financiero y tributario actual y Derecho fiscal romano, en Xornadas e Seminarios: Derecho Administrativo Histórico 1 (2005), pp. 77 y ss. Vid., al respecto, asimismo, en FERNÁNDEZ DE BUJÁN, A., Perspectivas de estudio en temática de Derecho Administrativo romano surgidas a tenor del pensamiento y de la obra de Giambattista Impallomeni, en Index 26 (1998), pp. 463 y ss.; Derecho administrativo histórico. Dir., Xornadas e Seminarios, Ed. Escola Galega de Administración Pública (2005); Instituciones, hechos y actividad de orden administrativo en la experiencia jurídica romana, en Xornadas e Seminarios: Derecho Administrativo Histórico 1 (2005) 119-158; Id., Derecho Público Romano, 12. a ed. (Madrid, 2009), pp. 232 y ss.

65 Especial relieve supuso respecto a la investigación del derecho administrativo romano, la aparición de la obra de SERRIGNY, Droit public et administratif romain 2 ( París, 1862). 
medios materiales precisos para hacer frente a la problemática planteada.

En la Roma republicana, todo ciudadano tenía el derecho y el deber de defender el orden constitucional, mediante la denuncia y puesta en conocimiento de las autoridades competentes, de todas las actuaciones que pudieran considerarse atentatorias contra la legalidad republicana. La labor de la policía judicial era, en ocasiones, facilitada por delatores, que a cambio de dinero, proveían de pistas a los servicios de seguridad. En otros casos, eran personas en situación de esclavitud quienes denunciaban a sus dueños o a otros ciudadanos, en espera de una recompensa. La populosa y cosmopolita Roma republicana, que llegó a contar con una población cercana al millón y medio de habitantes, no disponía, sin embargo, de una policía ciudadana que hiciese frente, de forma efectiva, a los graves problemas de seguridad y protección, que planteaba la convivencia ciudadana. Las labores de policía urbana en los barrios, vías públicas, tabernas, etc., estaban atribuidas a los ediles, que sancionaban, en la mayoría de las ocasiones, mediante multas, las contravenciones del orden ciudadano.

A lo largo de la etapa del Principado se crearon una serie de magistraturas con competencias urbanas, unipersonales o colegiadas: el perfecto encargado del cuidado de la provisión de víveres para la capital y de las distribuciones, el cuerpo de vigiles, los curadores públicos, los encargados del cuidado de los edificios públicos, acueductos, de las orillas del Tíber, espectáculos, casas de juego, moral pública, asociaciones, tribunales de justicia, etc. La configuración de la labor de policia como un servicio público, incardinado en el aparato administrativo estatal, es obra, en buena medida, de Augusto, que establece las bases de la policía urbana y provincial, con un criterio de jerarquía, de unidad de acción y de dirección permanente. La labor de la policía augustea se desarrolla en dos campos de actuación estrechamente interrelacionados: Un ámbito externo de investigación o espionaje, propio de la policía imperial o palatina, cuya dirección se atribuye al prefecto del pretorio o del Magister Officiorum y un ámbito urbano, municipal o colonial, que comprende labores de orden y vigilancia local, bajo la dirección del Prefecto de la ciudad y de los Prefectos de las distintas localidades.

En Roma las labores de policía diurna se atribuyen a las Cohortes urbanas, dirigidas por el Prefectus urbi, y a las Cohortes pretorias, dirigidas por el Prefecto del pretorio que tienen encomendados asuntos como la seguridad de la familia imperial. La policía nocturna estaba 
a cargo del Cuerpo de los Vigiles que, formado por 7.000 hombres, cumplía las funciones que tenía encomendadas o bien en puestos fijos, ubicados en lugares estratégicos de la urbe, o bien mediante rondas, realizadas por patrullas, que recorrían los distintos barrios de la ciudad. Con Vespasiano la policía de seguridad se atribuye al Cuerpo de los denominados speculatores y con Adriano esta labor se realiza por el cuerpo de los frumentarii, que comporta una mayor profesionalización como agentes encubiertos, del servicio secreto, con facultades de detención y encarcelamiento de los presuntos delincuentes, que debían ser puestos a disposición de la autoridad judicial o política, para su enjuiciamiento.

Diocleciano disuelve el cuerpo de los frumentarii y crea el de los agentes in rebus, con mayores competencias y facultades, y con la relevante diferencia de que los componentes de este nuevo Cuerpo de seguridad dirigido por el Magíster Officiorum, son agentes civiles y no soldados profesionales. Entre las nuevas funciones de estos agentes estaban el control y la supervisión de los propios Departamentos de la Cancillería imperial, lo que dio lugar, en algunos casos, a espinosos enfrentamientos, con ocasión de acusaciones más o menos fundadas de traición, negligencia o corrupción de los funcionarios que integraban las correspondientes secciones. Particular relieve, en esta etapa, adquiere la labor de vigilancia, control y persecución que durante siglos sufrieron los cristianos, por parte de los agentes secretos o encubiertos, a los que se les dio la denominación de beneficiarii y curiosi ${ }^{66}$.

El estudio, en definitiva, en el marco del Derecho administrativo romano, de la concepción y evolución habida a propósito de la conformación de la policía urbana, la policía exterior, la actividad de los delatores, el servicio de espionaje, la guardia pretoriana, o el servicio palatino de seguridad, como un mosaico variopinto de investigación, represión, seguridad, orden interno, corrupción, transgresión de facultades ejercitadas o abuso en el ejercicio de las labores legítimamente atribuidas, paradojas y enseñanzas de la historia, nos acercan al panorama que precisamente, en estos primeros años del tercer milenio, es objeto de análisis y denuncia en los medios de comunicación y en los tribunales de justicia, en relación con espionaje telefónico, programas de escuchas a particulares sin autorización judicial, espionaje en internet, venta de datos de información

${ }^{66}$ Vid., con carácter general, en FERNÁNDEZ ROSAENZ, El cuerpo de Vigiles, RGDR, Iustel, n. 2005; Id., Policía y Orden interno en Roma, Prólogo A. Fernández de Buján, Dykinson, en prensa. 
confidencial, corrupción de agentes de espionaje, etc. La historia de la humanidad se nos presenta, también en este punto, como un proceso continuado y gradual, con sus hitos, altibajos y retrocesos, en la búsqueda de una regulación que haga compatible, la necesaria seguridad de los Estados, con el escrupuloso respeto de las libertades civiles y las garantías de los ciudadanos. Eterno y clásico retorno de problemas, principios e instituciones en el mundo del derecho. Viejos ecos de conflictos entre el poder político, la legitimadad democrática y la razón de estado, en el logro de mayores cotas de libertad, seguridad y justicia.

En relación con los empleados públicos cabe señalar que a partir básicamente del Principado surge la figura del funcionario, si bien dicho término no fue utilizado por la tradición jurídica, quizá porque en contraposición a lo que ocurría con la concepción del magistrado, magistratus, republicano, los funcionarios no tuvieron un carácter jurídico unitario, por lo que se les atribuyeron denominaciones específica como praefecti, curatores, etc. ${ }^{67}$. En todo caso, se trataba de personas, que desarrollaban una actividad pública, bien en la Cancillería Imperial o bien en los distintos entes provinciales o locales ${ }^{68}$ y que eran titulares de un estatuto caracterizado de modo progresivo ${ }^{69}$ por notas como jerarquización, carrera administrativa, respeto a las formas, racionalidad y estabilidad, no obstante, en expresión de BRETONE, el grado de discrecionalidad permanente que derivaba de la actuación del Príncipe ${ }^{70}$.

$67 \mathrm{Vid}$, en este sentido STELLA MARANCA, Il diritto pubblico romano nella storia delle Istituzioni e delle dottrine politiche, Ann. Univ. Bari 2/1 1928, pp. 43 y ss; PALMA, Le cure pubbliche. Studi sulle strutture amministrative romane, Napoli 1980; PAVIS D'ESCURAC, La Prefecture de l'annone. Service administratif imperial d'Auguste à Constatin, (Roma, 1976).

68 En relación con la carrera administrativa de los funcionarios y magistrados en provincias vid. entre todos autores, MAGIONCALDA, Testimonianze sui Prefitti di Mesopotamia, SDHI (1982), pp. 167 y ss; CRISTOL-MAGIONCALDA, I procuratori Della Mauritania Sassari 1989. En relación con el cursus honorum, de los municipios y colonias vid. IMPALLOMENI, Un'epigraf concordiese in tema di Cursus Publicus in probabile relazione con CTh. 8.5.12 en Scritti cit., pp. 477 y ss.; D'ORS, La Ley Flavia Municipal (Roma 1986), pp. 131 ss.; MURGA, El delito de ambitus y su posible reflejo en las leyes de la Bética (Miskolc 1993), pp. 215 y ss.; CAIMI, Burocracia e Diritto nel De magistratibus de Giovanni Lido (Milano 1994).

69 Opina NOCERA, Il centralismo administrativo del Tardo Impero, Atti dell'Accademia romanística Constantiniana VIII 610, que no resulta censurable el epíteto de burocracia para referirse a la época del Tardo-Imperio, caracterizada por la confluencia del derecho constitucional con el derecho administrativo, como fuente unitaria del poder central.

70 BRETONE, Storia del Diritto Romano, (Roma Bari, 1989), pp. 250 y ss. 
Un estudio sistemático y de conjunto, acerca de la configuración y las competencias específicas, de los distintos administradores o agentes públicos, que de forma progresiva fueron conformando la Administración del Estado romano, ha sido realizado, en fecha reciente, por Carlos Varela, en el que se analizan aspectos como: acceso a la función pública, análisis de los funcionarios de hecho, derechos económicos (retribuciones y pensiones) y no económicos (derechos al cargo y a la carrera) de los empleados públicos, obligaciones (deberes, incompatibilidades, responsabilidad) y causas de la pérdida de la condición de administrador público. Del conjunto de los aspectos analizados cabría establecer dos grandes conclusiones:

A) La discrecionalidad del Emperador para intervenir en el funcionamiento y la estructura de la Administracion, si bien se tendió de forma paulatina, a una organización de tipo racional, impersonal y configurada con criterios objetivos, en especial en el ámbito de la gestión, y

B) Se distinguió en la Administración romana, entre cargos políticos o de alta dirección, caracterizados en cuanto al contenido de sus funciones, por la discrecionalidad en su determinación, y los puestos de empleados encargados de la gestión pública, caracterizados, en buena medida, y en mayor grado con el paso del tiempo, por las notas de racionalidad, estabilidad y profesionalidad, de los modernos cuerpos de funcionarios ${ }^{71}$.

Se produce asimismo en el Principado una funcionarización paulatina de la Justicia. A este proceso se refiere FERNÁNDEZ BARREIRO cuando escribe que la organización de la administración civil imperial, y el consiguiente desarrollo dentro de la misma de un nuevo sistema judicial funcionarial y tendencialmente burocrático, trae consigo un profundo cambio en la práctica del derecho y genera grandes posibilidades profesionales de acceso a las funciones de una administración cada vez más expansiva ${ }^{72}$.

En la República los magistrados, en el ámbito civil, estaban sujetos a la misma responsabilidad que el resto de los ciudadanos. En el

71 Vid. al respecto en Varela, C., El estatuto jurídico del empleado público en Derecho Romano. Prólogo de A. Fernández de Buján. Madrid 2007; Vid. asimismo en Malavé Osuna, El acceso y la promoción de los funcionarios en la administración del Bajo Imperio, «Revista de Estudios Histórico-Jurídicos», 27, 2005, pp. 101-121.

72 FERNÁNDEZ BARREIRO, El factor jurisprudencial como elemento de identidad de la cultura jurídica europea. Proyección histórica de la herencia jurídico-cultural romana. SDHI 1955, pp. 676 y ss. 
ámbito penal y administrativo ${ }^{73}$ era muy difícil llevar a un magistrado ante los tribunales en el período de ejercicio de su cargo, pero no así cuando el período de mandato hubiese transcurrido ${ }^{74}$. A finales de la República se plantean conflictos ante los tribunales que se consideran de responsabilidad administrativa, por ejemplo, indemnización irrisoria o exagerada en supuestos de expropiación forzosa, ganancias ilícitas en la contratación de una obra pública, etc. En las épocas del Principado y del Imperio acaba distinguiéndose al respecto entre responsabilidad penal, responsabilidad disciplinaria y responsabilidad derivada de los daños sufridos por el Fisco o por los particula$\mathrm{res}^{75}$, y así por ejemplo, en el ámbito de la responsabilidad civil, en el Egipto romano, los funcionarios, en el ejercicio de sus funciones, tenían prohibido prestar dinero, adquirir tierras de dominio estatal o cosas vendidas en subasta, a fin, con todo ello, de evitar extorsiones o perjuicios para el Fisco. En el ámbito penal, se tipifican asimismo determinados delitos que pueden cometer los funcionarios en el ejercicio de sus funciones, por ejemplo:

- Extorsión por pagos indebidos.

- Regalos obtenidos por abuso de poder.

- Apropiaciones indebidas de objetos, realizadas por funcionarios en viajes oficiales.

- Actuaciones atentatorias contra la seguridad pública.

- Delitos fiscales, etc.

De los daños causados por los funcionarios, por dolo o culpa, en el ejercicio de sus funciones, respondían los causantes de los mismos, no sólo en relación con las personas perjudicadas sino también en relación con el Fisco.

${ }^{73}$ En materia de concusión, corrupción cohecho y tráfico de influencias. Vid. GARCÍA GARRIDO, Precedentes romanos del tráfico de influencias. Lección inaugural del Curso 1992-93 UNED.

74 En relación con la responsabilidad por delitos o infracciones administrativas cometidas por magistrados locales en el ejercicio de su cargo, vid. MURGA, La popularidad de las acciones cit., pp. 260 y ss.

75 En el c. 67 de las leyes municipales de Málaga y de Irni, se regula la responsabilidad de los que manejan fondos públicos: «...qui rationes comunes negotiumne ... geserit tractavent ...». En el c. 82 de la Lex Ursonensis, se concede acción popular contra los magistrados que vendieren o arrendaren por más de 5 años los inmuebles propiedad de la colonia. En el c. 93 se concede acción popular a los colonos contra el magistrado que hubiese obtenido un beneficio como donación, regalo o recompensa (danum, amunus, mercedem) por la concesión de un bien público, tanto si fue concedido directamente, como si el concesionario se sirvió de una persona interpuesta; vid. asimismo en materias de daños CTh. 15.1.11 y 15.1.16. 
El absentismo laboral, regulado de manera precisa, generaba responsabilidad disciplinaria ${ }^{76}$. De manera minuciosa se regulaba, asimismo, la exigencia de responsabilidades por infracciones administrativas $^{77}$ y la actuación específica de los funcionarios de aduanas.

En los supuestos de confrontación entre intereses particulares e intereses de la comunidad política o Estado, queda configurada en sus líneas esenciales una jurisdicción que podría denominarse administrativa. Los litigios podían ser muy variados: disputa sobre límites entre propiedad pública o privada; ocupación por parte de particulares de campos de cultivo o pastos demaniales, construcciones ilícitas sobre campos de cultivo, pastos demaniales o suelo público, expropiaciones forzosas, apropiación indebida del agua pública, daños a las cosas públicas y, en general, cualquier tipo de litigio nacido de las concesiones administrativas de suelo público o de la adjudicación de obras y servicios públicos ${ }^{78}$.

La jurisdicción administrativa ha sido estudiada, entre otros autores, por MOMMSEM, DE RUGGIERO, CARRELLI y PUGLIESE ${ }^{79}$. Se trataba de litigios no sujetos a la jurisdicción civil ordinaria del pretor, sino a una especial, que fue atribuida en tiempos de la República a censores y ediles y en el Principado e Imperio a los diferentes cuestores de cosas públicas: aquarum, viarum, operum et locorum publicorum, metallorum, etc. Para mitigar el hecho de que en estos procesos el magistrado solía jugar el papel de juez y parte, solía cederse por parte del Estado los créditos, intereses o derechos a un tercero, ciudadano que ocupaba el primitivo lugar del populus. De esta forma un civis ajeno al conflicto se convertía en delegado de los intereses de la civitas.

Hay que tener en cuenta que es en el Principado ${ }^{80}$ cuando comienza la literatura sobre Derecho administrativo: De re militari, de

${ }_{76}$ CTh. 7.12.3.

77 En relación con la legitimación reconocida a cualquier ciudadano o a cualquier habitante de municipio o colonia para exigir responsabilidades por infracciones administrativas, vid. Murga, El delito de ambitus, cit., pp. 222 y ss.; con carácter general la responsabilidad de los funcionarios se regula en el liber 50 del Digesto. Así por ej. contra la inspección en el censo, como señala IMPALLOMENI, L'inquadramento giuridico delle colonie e dei municipi, cit. 36 cabía la posibilidad de presentar recurso administrativo.

78 DE RUGGIERO, L'arbitrato pubblico in relazione al privato presso $i$ Romani (Roma 1893)

79 PUGLIESE, Processo privato e processo pubblico en Rivista Diritto Processuale 3 (1948), pp. 63 y ss. Id. Figure processuali ai confini tra iudicia privata e iudicia publica en Studi Solazzi (Napoli, 1948), pp. 408 y ss.

${ }^{80}$ En relación con la jurisdicción del concilium principis, vid. entre otros autores, AMARELLI, Concilia principium (Napoli, 1983). 
iuri fisci, de officio consulis, de officio proconsulis ${ }^{81}$. Asimismo tiene importancia al respecto el hecho de que prestigiosos juristas desarrollasen una carrera administrativa importante en la burocracia imperial, por lo que debieron familiarizarse con el Derecho constitucional y administrativo. Pomponio recuerda a Tuberón como doctissimus iuris publici et privati y Gelio recuerda a Capitón como publici privatique iuris peritissimus, si bien, en opinión de NOCERA, es el período comprendido entre Constantino y Justiniano el más adecuado como fecha de referencia de los orígenes del Derecho público-administrativo ${ }^{82}$.

Diferente esfera de actividad administrativa sería el referente a la naturaleza, eficacia y validez de los actos administrativos: dentro de este marco habría que incluir la regulación de las actividades de los funcionarios de hecho: por ejemplo, el esclavo que se hace pasar por pretor o cuestor o que llega a ser senador, estableciéndose la convalidación de sus actuaciones o bien por causa de la utilitas pública o bien en atención a razones metajurídicas como la humanitas ${ }^{83}$.

Dentro del ámbito de la experiencia administrativa romana, escribe Riccobono, especial interés presenta el estudio de los interdictos públicos. La finalidad pública directa e inmediatamente protegida por los interdictos puede ser muy variada: desde la tutela de la salud pública, a la tutela del uso privado de los bienes públicos; desde la defensa pública del uso privado, a la tutela privada del uso público ${ }^{84}$. Sobre esta materia ha sido recientemente publicado un estudio monográfico, por Alburquerque. Cabe señalar con el autor que los interdictos, entendidos como órdenes de carácter administrativo, dirigidos a prohibir, restituir a la situación anterior o exhibir algo, tenían como finalidad mantener la paz social, y defender con carácter provisional, en aten-

81 Ya en la época de Cicerón, como señala este autor en su obra Pro Balbo 19,45, existían especialistas en Derecho constitucional y administrativo.

82 NOCERA, Il centralismo administrativo del tardo-impero, cit., p. 604.

83 En materia de funcionarios de hecho, vid. LUCIFREDI, Note per un'analisi di fatto della pubblica amministrazione, en Contributi allo Studio dell'esercizio di fatto di pubblice funzioni (Milano, 1965), pp. 117 y ss., CERAMI, Problema storico-dogmatici in tema di funcionario di fatto en St.Scaduto (Padova, 1970), pp. 397 y ss. Distingue este autor cuatro categorías clásicas de ejercicio de hecho de funciones públicas: ejercicio sin título, ejercicio con base en un título inválido, ejercicio con base en un título caducado y ejercicio con base en un título devenido inválido o ineficaz.

84 RICCOBONO, Il problema, cit, pp. 670 y ss.; ALBURQUERQUE, A propósito de las providencias-administrativas urgentes: los interdictos en Derecho Romano, Iuris Tantum (Univ. Anahuac, México, 1996), pp. 65 y ss. Resalta este autor la idea del interdicto como providencias administrativa urgente, y no como instrumento perteneciente a la esfera de la jurisdicción ordinaria. 
ción a la posible revisión en juicio ordinario, de forma sumaria, intereses públicos o privados. Podían tutelar instituciones previstas en el Edicto (interdicta edictales), conforme a esquemas abstractos tipificados en el álbum edictal, o situaciones no previstas (interdicta decretales). El procedimiento interdictal romano constituye el referente histórico de la actual regulación de los procesos sumarios, y de las medidas cautelares o aseguratorias (interdicto de obra nueva o caución por el daño temido, interdictum demolitorium y cautio damni infecti). Pues bien, el núcleo más antiguo de interdictos probablemente haya sido el constituido por aquellos destinados a la tutela del uso colectivo de las diferentes cosas o lugares de dominio público: interdicta de publicis locis: loca, itinere, viae, flumina, ripae. Mediante estas órdenes pretorias: se prohíbe que se introduzca algo en un lugar público, o que se realice algo que pueda causar daño, salvo que se disponga de autorización para ello (D. 43.8.2.pr.); se evita que se retenga lo que se ha hecho perjudicando a las vías o caminos públicos (D. 43.8.2.20); se posibilita que las vías o caminos públicos vuelvan a su anterior estado (D. 43.8.2.35); se otorga protección al arrendatario de un lugar público, con la finalidad de garantizar el pacífico disfrute del mismo (D. 43.9.1); se impide todo tipo de perturbaciones frente a quien intenta restaurar la vía o camino público (D. 43.11.1.pr); se prohíbe que se haga o ponga en un río público o en su orilla cualquier cosa que pueda entorpecer el estacionamiento o tránsito de la navegación (D. 43.12.1); se prohíbe realizar cualquier cosa en un río público o en su orilla que perjudique o impida que el agua fluya con la normalidad del anterior estío (D. 43.13. l .pr); se prohíbe que se impida navegar por un río público (D. 43.14.1.pr.); se prohíbe que se obstaculicen las obras realizadas en beneficio de un río público o de su orilla (D. 43.15. 1.pr.), etc. ${ }^{85}$.

En relación con los aspectos referidos a dominio público, utilidad pública y privada, y expropiación forzosa, cabe señalar que entre los administrativistas españoles actuales, han sido quizás PARADA VÁZQUEZ $^{86}$, PAREJO ALFONSO ${ }^{87}$ y GALLEGO ANABITARTE ${ }^{88}$ quienes

85 ALBURQUERQUE, La protección o defensa del uso colectivo de las cosas de dominio público. Prólogo A. Fernández de Buján, Madrid 2002. Vid. asimismo del mismo A. y de Pino Ruiz, Algunas notas referentes a la experiencia administrativa romana de protección de los recursos naturales, RGDR, n. 13, 2009.

86 PARADA VÁZQUEZ, Derecho Administrativo. Bienes públicos y urbanismo III, cit.

87 PAREJO ALFONSO, Dominio público: un ensayo de reconstrucción de su teoría general, en RAP, 3 cit., pp. 100 y ss.

${ }^{8}$ GALLEGO ANABITARTE, MENÉNDEZ REXACH, DÍAZ LEMA, El Derecho de Aguas en España cit. 45. Pone de relieve Gallego que la expresión dominio público, nace en Francia, donde quedó consagrada en el art. 538 del Código Civil de Napoleón, pero la idea de dominio público fue ya conocida y regulada en Derecho Romano. 
en mayor medida han destacado que el punto de partida para analizar y estudiar el dominio público es el Derecho Romano.

Gayo en su clasificación de las cosas que están fuera del comercio distingue entre cosas públicas (res publicae) y cosas privadas (res privatae $^{89}$. Marciano introduce en la clasificación la categoría de cosas comunes (res communes omnium) y de res universitatis ${ }^{90}$, y Justiniano integra ambas clasificaciones, distinguiendo entre res publicae, res universitatis, res nullius y res communes ${ }^{91}$.

Las res publicae son aquellas que pertenecen al pueblo, «publica sunt, quae populi romani sunt» nos dice Ulpiano ${ }^{92}$. Se distinguieron en Derecho Romano dos tipos de res publicae, las res publicae in publico uso, que eran aquellos bienes de titularidad pública destinados al uso colectivo y gratuito para todos los miembros de la comunidad, por ejemplo, aguas públicas, minas públicas, vías públicas, puertos, jardines públicos, etc., y las res publicae in pecunia populi o in patrimonio populi o fiscales, que eran aquellas cosas públicas que producían beneficios (económicos) al Estado. Esta segunda categoría de cosas se caracteriza por estar sujetas a un régimen jurídico semejante al de los bienes de los particulares, por lo que podían ser objeto de negocios jurídicos. Se corresponden con el actual concepto de bienes patrimoniales del Estado. Las res publicae in publico uso constituyen a su vez el antecedente de los hoy denominados bienes demaniales ${ }^{93}$.

La idea del dominio público se configura, por tanto, básicamente en torno a las res publicae in publico uso romanas, si bien la elaboración conceptual y dogmática de dicha idea se inicia en la Edad Media y se desarrolla en el Derecho consuetudinario francés, e incluso hay que esperar a la Revolución Francesa y al Código de Napoleón para que se consagre la expresión dominio público, de donde pasa a nuestro Código Civil y a la legislación europea en general. La evolución

89 Gai 2.10: Hac autem quae humani iuris sunt, aut publicae sunt aut privatae.

90 D.1.8.2 (Marc. 3 inst) quaedam naturali iure communis sunt omnium, quaedam universitatis, quaedam nullius, pluraque singulorum, quae variis ex causis cuique acquiruntur.

${ }^{91}$ Inst. 2.1.1: quaedam enim naturali iure communi sunt omnium, quaedam publica, quaedam universitatis, quaedam nullius pleraque singulorum, quae ex subiectis apparebit.

92 D.50.16.15 (Ulp. 10 ad ed) Bona civitatis abusive publica dicta sunt : sola enim ea publica sunt, quae populi romani sunt.

93 Son numerosos los textos que recogen la distinción entre ambas categorías de bienes públicos, así Pomponio en D. 18.1 .6 pr. (Pomp.9 Sab) ...aut quorum commercium non sit, ut publica, quae non in pecunia populi, sed in publico usu habeantur, ut est campus Martius. 
producida a propósito de la institución del dominio público, es significativa para argumentar que, frente a la opinión mantenida por algunos estudiosos, de que en el Derecho actual se conservan términos o expresiones jurídicas arrastradas desde el Derecho Romano, pero que tienen en la actualidad una significación diferente a la que tuvieron en sus orígenes, en el caso concreto de la expresión dominio público, como en tantos otros, la historia nos muestra que es la idea del dominio público la que fue conocida y regulada en Derecho Romano, como romanos son, por separado, los términos dominium y publicum, si bien hay que esperar a la Revolución Francesa para que dicha idea se plasme en la expresión dominio público.

En la República romana se entendía que la titularidad de las res in pecunia populi correspondía al aerarium, mientras que a partir del Principado la titularidad se le atribuye progresivamente al Fisco, de ahí la expresión de res in patrimonio fisci o res fiscales ${ }^{94}$.

Los otros términos de las categorías res universitatis y res communes se corresponden con las siguientes ideas: las res universitatis son unas cosas que pertenecen a la ciudad - y por extensión, en su caso, al municipio, colonia u otro ente público- y están destinadas al uso de la colectividad. Su régimen jurídico es el de res publicae ${ }^{95}$.

Las cosas comunes son aquellas que por razones de derecho natural (ius naturale) o de derecho de gentes (ius gentium) se considera que pertenecen a toda la humanidad, como el aire, el mar, las playas o el agua corriente. Se trata de una categoría de cosas, fundamentada en razones de tipo filosófico, pero que tiene consecuencias jurídicas ${ }^{96}$.

Las res publicae in publico uso lo son o bien en virtud de un acto de publicatio, o bien por razón de su destino o utilización pública, o bien por causas naturales ${ }^{97}$.

La publicatio consistía en una ceremonia en virtud de la cual un bien se transforma en público y se destina a la utilización colectiva. Se correspondería con lo que hoy se denomina afectación de una

94 D. 18.1.72.1 (Pap. 10 quaest.)... si quid sacri aut religiosi, aut publici est, ius nihil venit, si res non in usu publico, sed in patrimonio fisci erit, venditio eius valebit...

95 D. 1.8.6.1. (Marc. 3 Inst.). Universitatis sunt, non singulorum, veluti quae in civitatibus sunt theatra, et stadia, et similia, et si qua alia sunt communia civitatum...

96 D. 1.8.2.1 (Marc. 3 inst.). Et quidem naturali iure omnium communia sunt illa: aer, aqua profluens, et mare, et per hoc litora maris

${ }_{97}$ Quizás el texto fundamental en materia de publicatio, corresponde a Ulpiano y está recogido en D. 43.8.2.21: En materia de publicatio cabe consultar, entre otros autores, BRASIELLO, s.v. "Publicatio», in NNDI, XIV, pp. 585 y ss.; DE ROBERTIS, La espropriazione per pubblica utilitá nel diritto romano, in St. Zanobini, 1965, pp. 162 y ss. 
cosa al uso público. La publicatio era un acto administrativo, cuya competencia estaba expresamente atribuida a magistrados determinados, mediante el cual la cosa quedaba por tanto afectada o destinada al uso público.

Se entendía en otros supuestos que la cosa era pública por razones naturales o por naturaleza, lo que ocurría, por ejemplo, con los ríos perennes. Es la llamada afectación natural ${ }^{98}$. Por razón de su destino o utilización pública se consideraban en ocasiones públicas determinadas cosas sin necesidad del acto formal de la publicatio, así por ejemplo, la mera apertura al público de una carretera suponía su carácter público, sin necesidad de formalidad de ningún tipo ${ }^{99}$.

Hasta el Principado, fueron los censores los magistrados considerados competentes en materia de ius publicandi, es decir, con potestad para vincular al uso público las cosas. A partir del Principado, la competencia pasó al Príncipe y a los funcionarios especiales a los que se atribuye tal potestad ${ }^{100}$.

Podemos considerar, en síntesis, como notas características de las res publicae in publico uso las siguientes:

- Pertenencia al populus o a un ente público.

- Régimen de uso, regulado por el ente titular; y abierto a todos los miembros de la colectividad.

- Publicatio, destino natural o vetustas, en la caracterización como público del bien correspondiente.

- Inalienable: el bien está fuera del comercio.

- Imprescriptible: el bien no puede ser adquirido por usucapión de un particular.

- Nulidad de estipulaciones, legados, servidumbres, etc., realizadas sobre este tipo de cosas públicas ${ }^{101}$.

\footnotetext{
${ }_{98}$ Así por ejemplo en materia de afectación natural considera Ulpiano público un río, cuando es perenne, sin necesidad de declaración expresa por el Ordenamiento Jurídico: D. 43.12.1.2-3.

99 En relación con la administración de los bienes patrimoniales por los municipios vid. la referencia de IMPALLOMENI en L'inquadramento giuridico delle colonie e dei municipi, cit., p. 36.

100 En relación con los bienes públicos, ha utilizado Impallomeni su mencionado método interpretativo en su estudio titulado, La rade, i porti, le darsene e le opere a terra, cit. pp. 583 y ss.

101 Vid. al respecto en SALCILLES, Le domaine public a Roma et son application en matiere artistique Paris 1889: MURGA, La extracomercialidad de los bienes afectados a un destino colectivo en el Bajo Imperio Romano. Actas II Symposium Historia de la Administración. Madrid, 1971.
} 
Finalmente, en relación con la utilitas publica y la expropiación forzosa, cabría realizar las siguientes consideraciones: Hasta la época clásica coincide el significado de las expresiones utilitas publica, utilitas omnium y utilitas universorum ${ }^{102}$. La contraposición de intereses privados y públicos produce el resultado, con carácter general, de subordinación de los intereses privados, pero entendiendo que ello se hace en utilidad del pueblo en su conjunto, no de un ente estatal o abstracto como el Estado romano. A partir de la época clásica y de manera especial en la época postclásica, se introduce ya claramente en los textos la idea de utilidad del Estado o del Fisco, llegándose a considerar que lo que es de utilidad pública, es decir, del Estado como ente abstracto o de otros entes públicos, como pueden ser los intereses meramente fiscales o recaudatorios, podría no ser de interés o no coincidir, al menos en una primera instancia, con los intereses de los particulares o incluso de la colectividad en cuanto tal. Se trata de que prevalezca ante todo el interés superior del Estado, al entenderse que ello, en definitiva, constituye en último extremo el interés común ${ }^{103}$. En materia de urbanismo, en general, y de disposiciones administrativas relativas a límites de altura de los edificios, demolición de construcciones por voluntaria omisión de los propietarios de los cuidados de conservación, demolición de edificios nobles para negociar con sus materiales, restauración obligada de edificios, etc., cabe señalar un estudio al respecto de Varela Mateos ${ }^{104}$.

En materia de expropiación cabe recordar, en primer lugar, la relevancia que en el mundo romano tuvieron las obras públicas, lo que supuso en muchas ocasiones confrontación entre intereses públicos e intereses privados. Se contienen en las fuentes numerosos textos en los que, dependiendo de las épocas, se plantean y resuelven supuestos de prevalencia del interés privado y de la propiedad particular sobre el interés público, supuestos de expropiación forzosa con

102 En materia de utilitas publica, vid., entre otros autores, LONGO, Utilitas publica, in Labeo, 1972, pp. 7 y ss.; GAUDEMET, Utilitas publica, in RH. 1951, pp. 465 y ss.; ARIAS BONET, Dominio y utilidad pública en Derecho Romano, in Est. Pérez Serrano, cit., pp. 41 y ss.; Alburquerque, Notas acerca de la utilitas publica, «RGDR» Iustel, 5, diciembre 2005.

103 Sobre la concepción de la acción popular como una vía procesal que protegía un interés público, aunque también suponía la propia ventaja personal del actor, en cuanto que el denunciante sería el beneficiario de la multa, vid. FADDA, L'azione popolare. Studio di diritto romano e attuale (Roma, 1894).

104 VARELA MATEOS, La reconstrucción de los edificios privados en la Roma clásica y un discutido Senadoconsulto de la época de Marco Aurelio, in Est. Hernández Tejero, Madrid, 1994, pp. 539 y ss.; Id., El grave problema de la conservación de los edificios privados en la Roma clásica, in Est. Vallet de Goytisolo, IV, pp. 847 y ss. 
indemnización y supuestos de confiscación, es decir, de expropiación sin indemnización.

Si bien no existió en Roma una ley general reguladora de la expropiación forzosa, sí se conocen numerosos casos en los que la expropiación tuvo lugar por razones de utilidad pública o de interés social, tanto respecto de bienes muebles como de bienes inmuebles ${ }^{105}$. LOZANO en una reciente monografía sobre la expropiación forzosa llega, entre otras, a las siguientes conclusiones:

1. El título de la expropiación forzosa fue, primero, la necesidad pública y después la utilidad pública, unidas al principio del mínimo sacrificio de la propiedad privada, y de la libertad de los ciudadanos romanos.

2. La expropiación forzosa, por causa de utilidad pública y en interés del bien común, estuvo siempre unida, vinculada, a la entrega de una compensación o indemnización, que no representó solamente el valor o precio de la cosa a expropiarse, sino la completa reparación y el pleno resarcimiento de los daños, que el sujeto expropiado sentía directa y necesariamente, a causa de la propia expropiación forzosa.

3. Fue la expropiación forzosa, por causa de utilidad pública y en interés del bien común, un instituto dotado de autonomía jurídica.

4. Existió un procedimiento expropiatorio, elástico en la forma, pero fundado sobre el genérico poder perteneciente a todo magistrado de mandar y de ser obedecido en el ámbito de sus atribuciones.

5. El instituto de la expropiación forzosa surgió y se desarrolló en la esfera de la praxis administrativa, fundado sobre la costumbre constitucional y, por lo tanto, salió completamente de la órbita jurídica privatística.

6. En cuanto a la naturaleza jurídica del derecho de expropiación forzosa, en el Derecho Romano, se nos presenta como una relación obligatoria entre el populus Romanus y el ciu-

105 Vid. en materia de expropiación, entre otros autores, DE ROBERTIS, La espropiazione per pubblica utilitá nel diritto romano Bari 1936; LOZANO, La expropiación forzosa, por causa de utilidad pública y en interés del bien común, en el Derecho Romano, Zaragoza 1994; PONTE ARREBOLA, V., La expropiación forzosa en la construcción de vías públicas romanas a la luz de la legislación municipal y colonial, «RGDR» (www.iustel.com), 10, julio, 2008. 
dadano, que se perfeccionaba con el consentimiento, por parte de este último, cediendo la cosa, objeto de la expropiación forzosa. Los romanos, teniendo presente este segundo momento, estaban inclinados a considerar el instituto como una venta forzosa, como una venta no espontánea, como una emptio ab invito.

7. Dentro del objeto de la expropiación forzosa se comprendían todos los bienes privados sin excepción.

8. La necesidad de fijar una indemnización o una compensación, que debería entregarse al sujeto expropiado, debería ser lo establecido y darse siempre. Sería concretada para cada caso o supuesto concreto de expropiación forzosa, sin atenerse a ningún procedimiento previo establecido, sino ad casum.

9. La declaración de utilidad pública en el Derecho Romano pertenecería al "poder ejecutivo», hablando en pura terminología moderna, o, si se desea, a la «Administración pública». Se concretaría, probablemente, esta declaración de utilidad pública y, por tanto, la necesidad de la expropiación forzosa, por causa de utilidad pública y en interés del bien común, con la posible y probable emanación de un decreto.

10. El ciudadano particular, que se creyese injustamente lesionado a causa del ejercicio, por parte del populus Romanus, del derecho de expropiación forzosa, por causa de utilidad pública y en interés del bien común, tenía derecho a defenderse bien contra el propio magistrado competente para llevar a cabo la expropiación, o bien frente a la propia Administración pública, o, si se desea, frente al populus Romanus.

11. El magistrado competente podría ser responsable, frente al ciudadano expropiado forzosamente, por causa de utilidad pública, pero esta responsabilidad sólo podría versar sobre la determinación del importe de la compensación, si ésta era inferior al valor real de la cosa expropiada.

12. También el magistrado podría responder frente al propio populus Romanus o, si se desea, la propia «Administración pública», si se le otorgaba al ciudadano una indemnización muy superior al valor real de la cosa expropiada.

Cabría afirmar, para concluir el presente apartado, que a la deseable conexión, tan necesaria para el progreso de la ciencia del Derecho, entre la elaboración dogmática del moderno Derecho admi- 
nistrativo y las aportaciones de la moderna investigación histórica correspondientes a la experiencia administrativa romana, se refiere IMPALLOMENI, en el párrafo final de su artículo sobre municipios y colonias, cuando manifiesta que uno de los mejores estudios sobre Derecho administrativo romano continúa siendo el debido a SERRIGNY — escrito en el siglo pasado-, docente de Derecho administrativo de la Universidad de Lyon: en él aparecen los paralelismos y comparaciones con el Derecho positivo francés. Y sería conveniente -concluye IMPALLOMENI- una labor de actualización de esta obra, y de extensión al Derecho de los otros países con ordenamientos derivados del Derecho Romano ${ }^{106}$.

106 IMPALLOMENI, L'inquadramento giuridico delle colonie e dei municipi, cit., p. 38 . 